\title{
LA FORMA LITÁNICA EN EL TEATRO. SIGLOS XVI-XVIII
}

\author{
JOSE FRADEJAS $\mid$
}

\section{S. XVI}

Al igual que en el teatro griego, como. afirma Rodríguez Adrados ${ }^{2}$, existen en el teatro español desde su origen en el $\mathrm{s}$. XV villancicos y canciones, monódicas y corales.

Pero tras la discusión de si la Cántica Eya velar es lírica o teatro, no habia aparecido ningún texto hasta la segunda mitad del s. XVI ${ }^{3}$, en que en el Códice de autos viejos se incluye la Farsa de los lenguajes ${ }^{4}$, un poema de tipo religioso que incide en la forma litánica:

$$
\begin{gathered}
\text { Cristo con amor es visto } \\
\text { dado como enamorado. } \\
\text { Jesucristo en quien creemos } \\
\text { Dado como enamorado. } \\
\text { Con la luz de fee le vemos. }
\end{gathered}
$$

1 J. Fradejas, «La poesía litánica hasta Berceo», Actas de las Terceras Jornadas Berceanas, Logroño, 1981, págs. 63-67; La forma litánica en la poesia popular, Lección inaugural del curso 1988-1989, UNED, Madrid, 1988; "La forma litánica en la poesía del s. XX», Revista de Literatura, 1996, LVIII, n. ${ }^{\circ}$ I I6, pags. 399-425; "La forma litánica en el mundo islámicon, Mélanges Maria Soledad Carrasco Urgoiti, Túnez, Fundation Temimi, 1999, II, págs. 37-44; «La forma litánica en Iberoamérica» (en prensa).

${ }^{2}$ F. Rodríguez Adrados, Origenes de la linica griega, Madrid, Revista de Occidente, 1976, pág. 88.

${ }^{3}$ No es exacto del todo. P. M. Cátedra ha hallado un manuscrito de entre 1410-1425 donde aparece una forma litánica iniciada por un trístico:

$$
\begin{aligned}
& \text { ¿Bien vengades, } \\
& \text { los pastores } \\
& e, \text { bien vengades! }
\end{aligned}
$$

Este tercer verso es el estribilio que se repite cada dos versos. Y, al parecer del Dr. Cátedra, este manuscrito es quizá el «eslabón perdido entre el teatro latino religioso y el de finales del s. XV y principios del XVI), $A B C$ del 8-VII-98.

${ }^{4}$ Códice de Autos viejos, ed. L. Rouanet, Hildesheim, G. Olms, 1979, IV, pág. 345.

RFE, LXXXI, 2001, $1 .^{\circ}-2 .^{\circ}$, págs. 89-135 


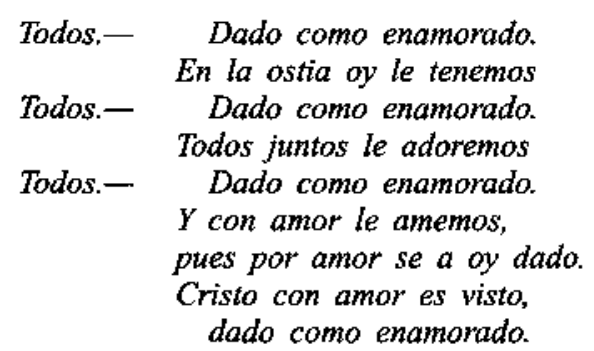

Su utilización en el teatro, su presencia como endecha, en el mundo turco según nos recuerda el Viaje de Turquia ${ }^{5}$.

El sentido religioso coincide con la noticia de Oliver Asín de que Fray Hernando de Talavera utilizaba esta forma con afán misionero y seguramente los moriscos la utilizaban, también, en función religiosa ${ }^{6}$.

Otro aspecto, importantísimo, el coral: el manuscrito no está manipulado y cuatro veces, ante el estribillo, se nos advierte que debe ser dicho por T o d o $\mathrm{s}$, lo cual nos lleva a corroborar su carácter musical y coral.

No es menos cierto, como puede verse en La forma litánica en la poesia popular, que la forma más simple - quizá de origen nacional- era frecuente ya en trísticos (Hernán González de Eslava, Cervantes, Lope, Tirso y Calderón), ya en coplas (Timoneda, Sánchez Badajoz, Cervantes, Lope ...). Por la misma época —-mediados del s. XVI- Jorge de Montemayor nos sorprende con este poema:

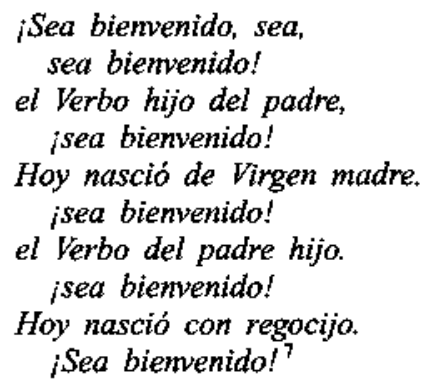

De forma, pues, que nos encontramos la supervivencia de la forma en la poesía lírica y en el teatro del $\mathrm{s}$. XVI, en ambos con sentido religioso, pero en Jorge de Montemayor con aspecto heroico o triunfal ${ }^{8}$.

${ }^{5}$ Viaje de Turquia, ed. F. García Salinero, Madrid, Cátedra, 1980, cap. XV, pág. 398.

${ }^{6}$ J. Vernet, Literatura árabe, Barcelona, Labor, 1968, pág. 246.

${ }^{7}$ Jorge de Montemayor, "Three Autos of ...», ed. Florence White, PMLA, 1928, XLIII (Auto Tercero, versos 46-55), pág. 977.

${ }^{8}$ Simultáneamente, Diego Femández, el Palentino, en su Historia del Perí (Sevilla, 1571), refiriéndose a don Fray Jerónimo de Loaysa (Arzobispo de Lima), gran ajedrecista y a Her- 


\section{S. XVII}

De todos los textos teatrales, con su enorme valor poético, el más significativo - por lo que veremos más adelante- quizá sea este de Simón Aguado, en su entremés Los Negros, publicado en 1602.

Pero la característica es que aparezca una tradición naïf en boca de negros que, sin duda, ya era tradicional entre ellos como producto de otra tradición, no la popular ni la litúrgica cristiana, ni siquiera la teatral española, sino la refleja o derivada de la religiosa misional musulmana en el mundo centroafricano que ya se habia popularizado, con todo su valor primitivo y que, sin duda, cantaban y bailaban los esclavos negros que existian en el mundo hispánico. He aquí este significativo texto, anticipo, si se quiere, de lo que veremos en el s. XX en El Caribe.

Son dos textos en que se incluye, junto al sentido festivo — canción de boda- el carácter de danza coral ya observado en textos anteriores:

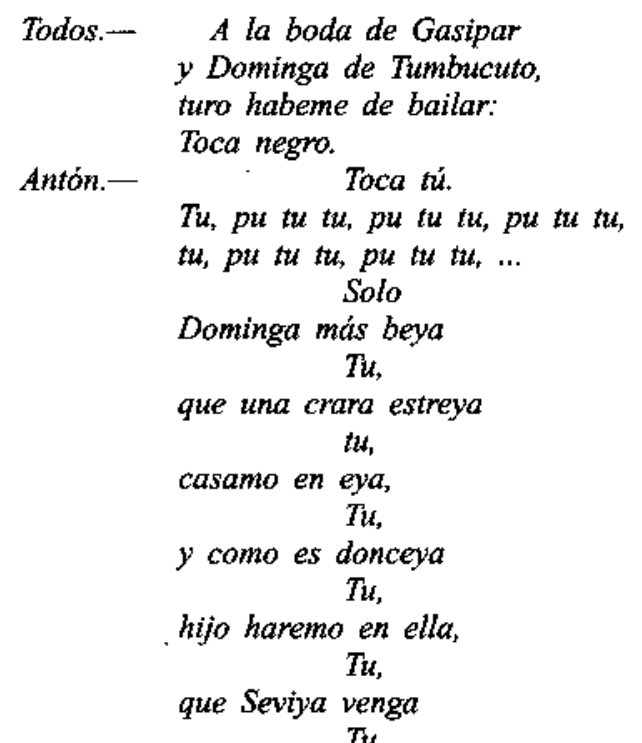

nando de Santillán, el Tranquilo, nos conservó este "chiste que siempre cantaban los soldados» en la revuelta de Francisco Hernández de Girón, allá por 1553-1554:

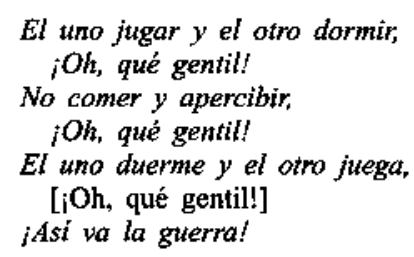


$y$ con mucha hacienda

Tu,

se vista de sera.

Tu,

y traiga a las fiestas,

Tu,

pajes de librea

$T u$,

lacayos mantenga.

$T u$,

las damas le quieran

tu,

$y$ que tantas gracias tenga que no haya más que mirar.

A la boda de Gasipar

y Dominga de Tumbucutu, turo habemos de bailar:

Antón.-

Toca negro.

Todos.- Tu, pu tu tu

Toca tú.

solo

En tu deposorio,

$T u, p u t u t u$

le daremo a tonos,

Tu,

canelonen gordos,

$T u$,

torta y bicicochos,

tu,

rábano y cohombre

tu,

perejil $y$ repoyo.

$\mathrm{Tu}$,

pasas y mondongo,

$\mathrm{Tu}$,

$y$ tintiyo de Toro

Tu.

calabaza y hongo,

$T u$.

culantriyo de pozo,

Tu, pu tu tu

y porque los novios,

$t u$,

duerman con reposo,

$T u$

un caldiyo de poyo,

$T u$,

Tanta vida les dé Dios

cuanta puedan desear 


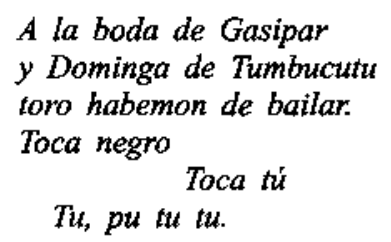

Simón Aguado, Entremés de los Negros ${ }^{9}$.

En este sentido, y muy pocos años después (siete), incide en la poesía de don Luis de Góngora:

\author{
Zambambú, morenica de Congo \\ Zambambú \\ Zambambú, que galana me pongo \\ Zambambú. \\ En la fiesta del Santísimo Sacramento $(1609)^{10}$.
}

Es, sin duda, imitación de un baile negro, con carácter popular, incrustado en su poesía culta. No forma parte del teatro y quizá debiéramos incluirlo en la forma lírica popular medieval y renacentista pero, debido al carácter onomatopéyico que le aproxima al Tumbuctú de Agudo, me ha parecido oportuno incluirlo aquí.

\title{
LOPE DE VEGA
}

Moda a la que no escapó Lope que, con su percepción poético-musical, captó inmediatamente los valores de este tipo, si no es que intuyó - como es la realidad - el arcaísmo de su origen y lo plasmó por dos veces en $L a$ victoria por la honra, con su lenguaje de negro bien expresivo y poco comprensible a veces $y$, a veces, totalmente irregular.

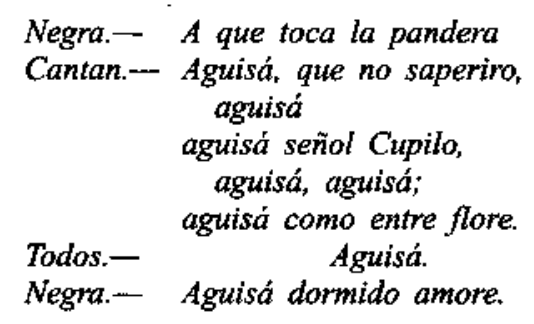

"Simón Aguado, «Entremés de los negros», en E. Cotarelo, Colección de Entremeses ..., Madrid, Baylli-Baylliere, 1911, NBRE, I, vol. I, págs. 231-235.

${ }^{10}$ Luis de Góngora, Obras Completas, ed. Juan e Isabel Millé, Madrid, Aguilar, S.A., letrilla 98, pág. 350 . 

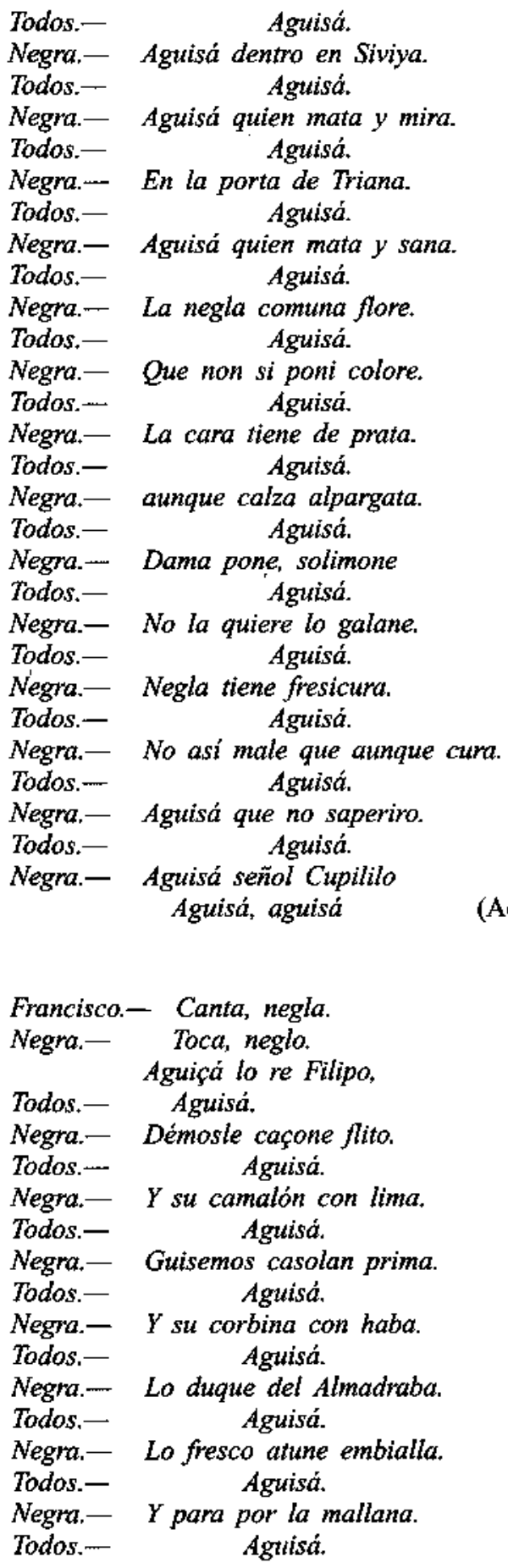


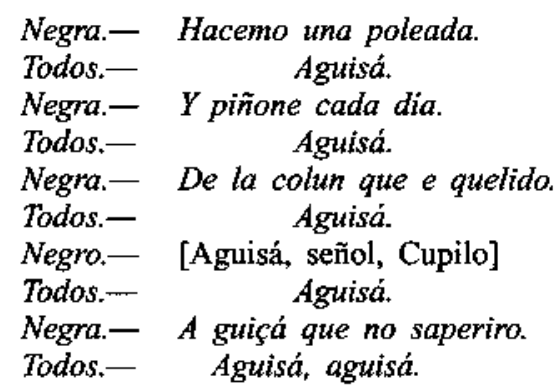

La Victoria por la honra, 1609-1612, N.Ac.X., acto I, pág. 423.

Forma en la que insistió en El capellán de la Virgen (1615), ciertamente regular dentro de cierta irregularidad.

Enträndose las hermosas

Labradoras de la Sagra,

Ellos, con disfraces negros,

Este villancico danzan:

El hocico de vosa mesé,

iHe, he, he!

Me tiene perim,

iAy, ay, he!

De amore venciro.

iAy, ay, he!

¿Que me moriré!,

iAy, ay, he!

¿Que me moriré!

El hocico neglo,

iHe, he, he!

$Y$ lo diente dentro,

iAy, ay, he!

Blanco sobre prieto,

iHe, he, he!

Neglo tiene muerto,

iHe, he, he!

Si non da remedio,

¡Triste yo! ¿Qué haré?

El hocico de vosa mesé,

jAy, ay, he!

Me tiene periro

[iAy, ay, hel]

De amore venciro

iAy, ay, he!

¿Que me moriré!

iAy, ay, he! 


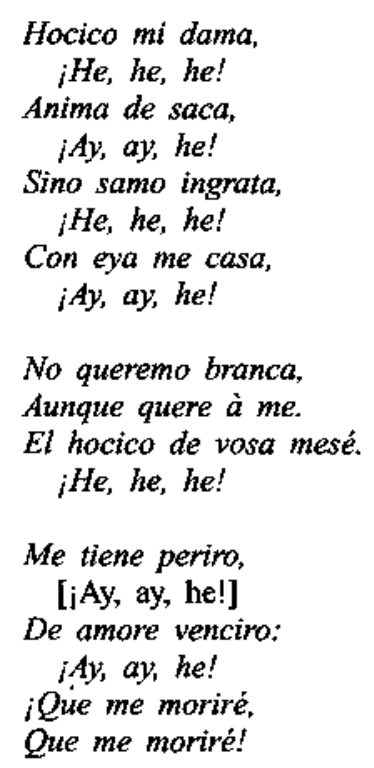

El capellán de la Virgen (1615), BAE, CLXXVIII, acto III, págs. 314-315.

Los tres grupos se inician con verso decasílabo: El hocico de vosa mesé y suele terminar con una aleluya exasílaba, como el resto de la canción excepto el estribillo tetrasílabo: $A y, a y, h e$, con la variante $H e$, he he. He aquí una primera irregularidad; otra es la falta de aleluya en el segundo tro$z 0$ interrogativo $y$, por fin, el final repite la cabeza.

La misma irregularidad se observa en la rima: consonante al comienzo $\mathrm{y}$ al final; consonante con un asonante en el segundo trozo y asonante en el segundo trozo.

Es una canción de danza en que los villanos, disfrazados de negros, bailan; tiene, pues, que ser regular y semejantes el comienzo y el final y pariguales el primero y segundo trozos, por eso he incluido tres correcciones que — dada la perversa conservación de los textos- dan mayor regularidad a la danza.

En el mismo sentido y con el estribillo $; H e$, he he! que aparece en $E l$ capellán de la Virgen, aunque en forma irregular, aparece en La limpieza no manchada que, por un lado continúa el baile y lengua negros y tiene también forma litánica regular.

(Bailen los negros)

De culebra que pensamo morde a Maria lo pe. 


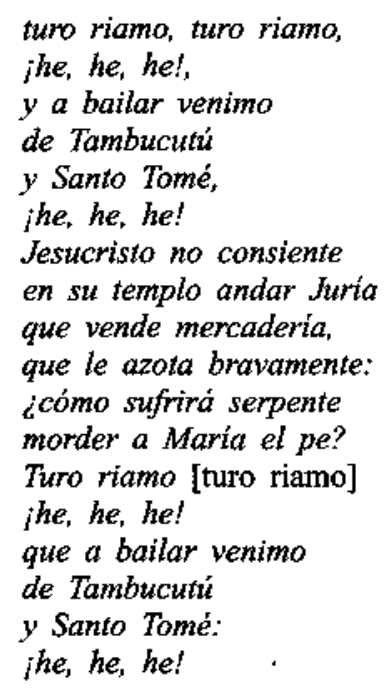

La limpieza no manchada (1618),

BAE, t. CLXXXVII, acto III, págs. 192a-b.

Ya había utilizado, como veremos, la forma regular en La tragedia del Rey don Sebastián, tomada de la tradición hispánica que inició Gonzalo de Berceo y que, según afirmó Oliver Asín, utilizó también don Fray Hernando de Talavera imitando, quizá, a los moriscos granadinos y que hemos visto anteriormente en la lírica y en el teatro, cuando, con anterioridad a la difusión del baile negro de Simón Aguado, utilizó repetidas veces la forma pseudo-litánica, porque ora es un carmina triunfalia coral pues el texto así nos lo dice cuando se refiere a un cantar (uno y otro) y un coro (todos): el corego entona en halago al Rey de Castilla y otro entona un dístico exasílabo sin rima que, $\sin$ duda, tiene ritmo y música que previenen el estribillo del coro: Que le guarde Dios.

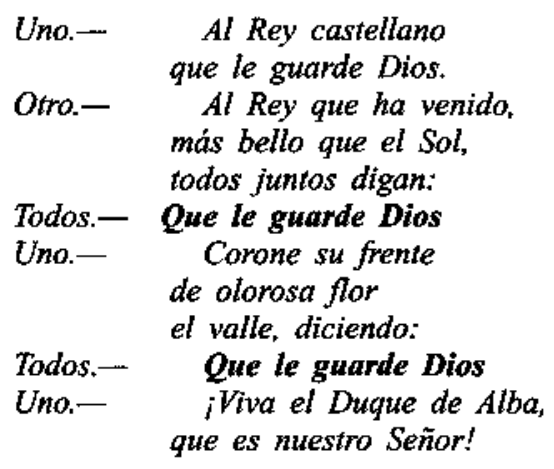




$$
\begin{array}{lc} 
& \text { Digan sus vasallos: } \\
\text { Todos.- } & \text { Que le guarde Dios } \\
\text { Uno-- } & \text { Montes de Batueca, } \\
& \text { que de nieve sois, } \\
& \text { decid humillados: } \\
\text { Todos.- } & \text { Que le guarde Dios. } \\
\text { Uno.- } & \text { Al Rey castellano, } \\
& \text { más bello que el Sol, } \\
& \text { todos juntos digan: } \\
\text { Todos.- } \quad \text { Que le guarde Dios. }
\end{array}
$$

Las Batuecas del Duque de Alba (1598-1600), $\mathrm{BAE}$, t. CCXV, acto II, pág. 385.

En esta dirección continúa innovando Lope; traslada a América en $E l$ Arauco domado la forma litánica - donde hoy pervive pujantísima- y con el héroe epónimo del Arauco, el Toqui rubendariano, Caupolicán, como estribillo.

Es un poema ágil y repetitivo, apto no sólo para el canto sino también para la danza:

(Salen INDIOS MÚSICOS delante, con unos tamborilillos, y por ser fuerza para cantar, con sus guitarras. $Y$ detrás, CAUPOLICÁN, con todos sus soldados. Y pónganse arriba en el fuerte los españoles con sus armas.)

$$
\begin{aligned}
& \text { Una voz.- Pues tantas victorias goza } \\
& \text { de Valdivia y Villagrán ... } \\
& \text { Todos.- Caupolicán. } \\
& \text { Solo-_ También vencerá al Mendoza } \\
& \text { y a los que con él están ... } \\
& \text { Todos.- Caupolicán. } \\
& \text { Solo-_ Si sabias el valor } \\
& \text { de este valiente araucano, } \\
& \text { a quién Apó soberano } \\
& \text { hizo de Arauco señor, } \\
& \text { ¿cómo no tienes temor? } \\
& \text { Que si venció a Villagrán ... } \\
& \text { Solo- - También vencerá al Mendoza } \\
& \text { y a los que con él están. } \\
& \text { Todos.- Caupolicán. } \\
& \text { Solo- Españoles desdichados, } \\
& \text { en ese corral metidos, } \\
& \text { que es confesaros vencidos, } \\
& \text { y que estáis juntos atados. } \\
& \text { ¿a dónde vais engañados? }
\end{aligned}
$$




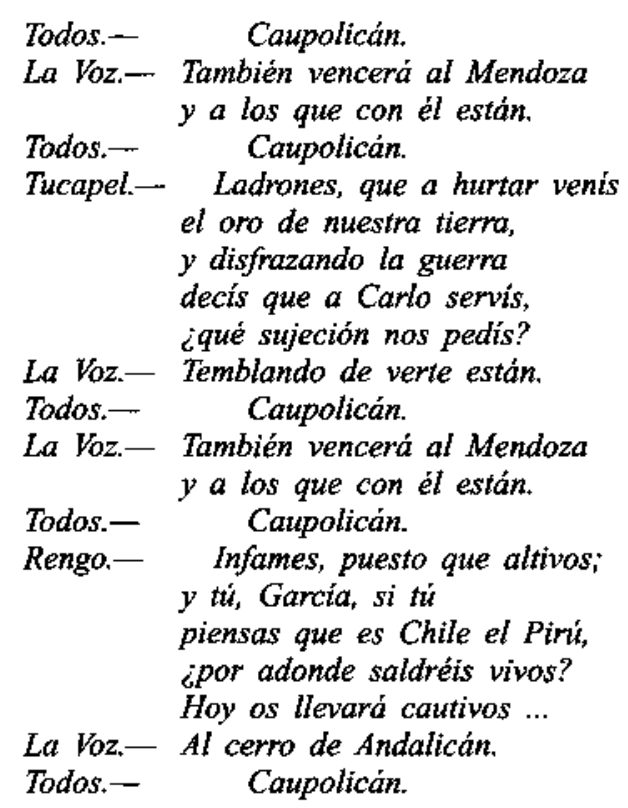

Es, una vez más, una canción coral: en el texto, no mal conservado, se nos advierte: el corego o cantor ora es una voz solo, Tucapel o Rengo y el estribillo es el más simple y sencillo: Caupolicán, un pentasílabo frente a los octosilabos de las estrofas, por lo cual es irregular: unas son cuartetas, quintillas, trísticos, a veces repetidos como doble estribillo.

Otra forma más próxima a la regular:

Cantan [los indios] Runfalalá, que no toca a la Niña, runfalalá, la culpa de Adán

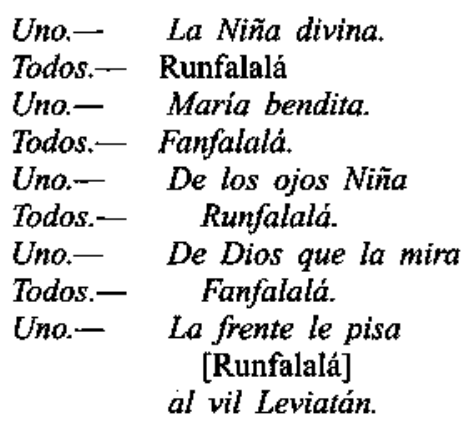



Todos.- Runfalaló, que no toca a la Niña Runfalalá, la culpa de Adan.

La limpieza no manchada (1610-1612),

BAE, 187, acto III, pág. 191a.

Casi igual, y con cierto paralelismo, aparece ahora cantado por indios.

Hemos visto vizcaínos, indios, labradores cantando; parece que nos faltaban los judíos, pero helos aquí:

Salen los músicos de judios, y los que bailan; canten y bailen.

Nunca el sol salió más bello, runfalalén.

Ni con más lindo cabello, fanfalalán.

Nunca fue tan claro el dia. runfalalén,

ni trajo tanta alegría, fanfalalán.

Que se alegren manda el cielo, runfalalán.

Todos los hombres del stuelo, fanfalalán.

No sabemos la ocasión, runfalalén,

pero alegrarse es razón, fanfalalán.

Por septiembre primavera, runfalalén.

¿Quién ha visto, o verla espera? fanfalalán.

Cuando nace algún cometa, runfalalén.

está la tierra sujeta, fanfalalán.

Mas cuando nace una hembra, runfalalén.

Que no hay sol que más alumbre, fanfalalán.

todos contentos están, fanfalalán.

La madre de la mejor (1618), BAE, t. CLIX, a. II, pág. 203.

Dos estribillos pentasílabos onomatopéyicos y lúdicos; seis aleluyas consonánticas octosílabas, dos versos libres octosílabos que sólo en la última 
sílaba (hem-bra, lum-bre) tienen cierta semejanza y un tercero que rima con el estribillo.

Poema francamente delicioso, en elogio de la Virgen María.

Algo semejante, en cuanto a irregularidad, ocurre en el auto sacramental La margarita preciosa, pero que corregida quedaría así:

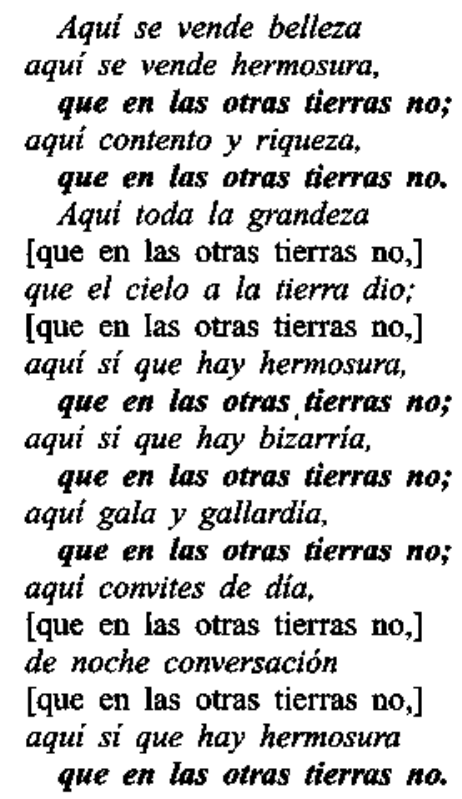

(BAE, t. 158, pág.165).

Sigue la irregularidad Lope en una canción deliciosa en honor de doña Isabel de Valois y de Felipe II, quizá por ello nos encontramos dos estribillos: Sea bienvenida (que en masculino ya había utilizado Jorge de Montemayor y utilizará Lope, también, en Los Tellos de Meneses) y Venga norabuena (utilizado en Los Guzmanes de Toral, en un trístico litánico, en Las grandezas de Alejandro y en La juventud de San Isidro, 1622).

Una vez más, los exasilabos cantóricos - "canten vascos (vizcaínos)》rimados en asonante $o-a$ e $i-o$, pero a la vez aparecen otras rimas extrañas: $o-a$ (aislada) o $e-a$.

Irregularídad de la forma litánica en cuanto a estribillos y rimas, pero perfecta canción - aunque no lo indique el texto- de bienvenida:

Sea bien venida

la reina linda

sea bien venida;

venga el sol de España

muy en hora buena. 
norabuena venga

la linda señora.

Sea bien venida

para ser aurora,

sea bien venida.

De Francia dichosa

sea bien venida.

Guipuzcoa la adora;

sea bien venida,

provinciana toda,

[sea bien venida]

que no vizcaina;

sea bien venida,

la reina linda,

sea bien venida.

Felipe divino

venga norabuena,

los, franceses lirios, vengan norabuena;

junte a sus castillos,

venga norabuena;

que duren mil siglos,

venga norabuena:

mas no vizcaino,

[venga norabuena;

guipuzcoano sea

venga norabuena,

norabuena venga

venga norabuena.

Los ramilletes de Madrid, 1615 ,

N.Ac. XIII, acto III, pág. 495.

Ciertamente aparecen algunas otras formas irregulares con estribillos lúdicos en Lope de Vega como, por ejemplo, esta del auto sacramental La Araucana (1590?):

\author{
Cantan \\ Farua, farua \\ el gobierno merece \\ Caupolicán \\ farua, farua, \\ $Y$ por el madero; \\ surrua, surrua, \\ en los hombros puso; \\ surrua, surrua, \\ nuestro triunfo veo; \\ surrua, surrua, \\ y al compás del premio, \\ nuestra libertad;
}


(BAE, t. CLVIII, pág. 426a).

Dos estribillos lúdicos: farua, farua y surrua, surrua, tetrasilabos; y otro repetido al comienzo y al final compuesto de heptasílabo y pentasílabo con cuatro exasilabas asonantadas en $-e o$ y un verso (nuestra libertad) que es asonante con Caupolicán.

Canción también americana, con formas lingüísticas de tan pura invención como:

\section{Piraguamonte, piragua piragua, jevizarizagua.}

En esta última - a lo que mi se me alcanza- se nos presenta, dentro de la irregularidad, incrustada una forma regular en versos exasílabos; asonantes en $-o$ los cuatro primeros y los cuatro últimos justamente con el estribillo y los tres versos litánicos asonantados en $i-a$, que a su vez riman con Niña y cautiva.

Canción nacional-católica: cantan ante España los labradores en loor de María:

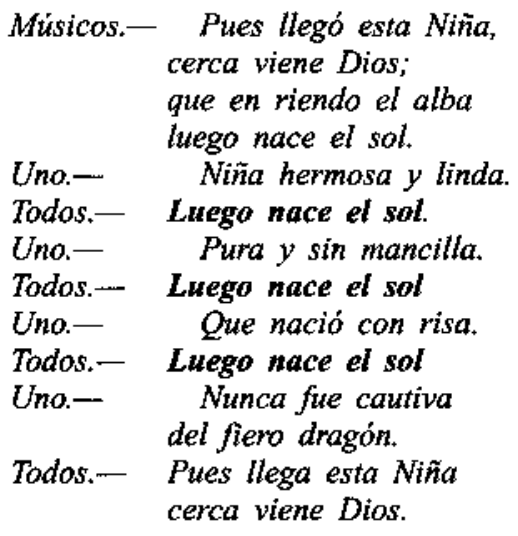

La limpieza no manchada (1618), BAE, t. CLXXXVII, A. III, págs. 188b-189a.

Es indudable su intención musical coral, una mujer inicia la canción, a la que responden todos. Es canción en loor de la Virgen de la Cabeza en octosílabos, mientras que el estribillo es un tetrasílabo: es un poema mono- 
rrimo en $e-a$, excepto dos versos que riman en consonante (doncella-vella), situados aproximadamente en el centro, que riman en consonante con el estribillo. Esta es la primera canción regular:

Siéntense a merendar y beber. Otro por otra parte con la misma música a plantar otra tienda enfrente, y diga una mujer:

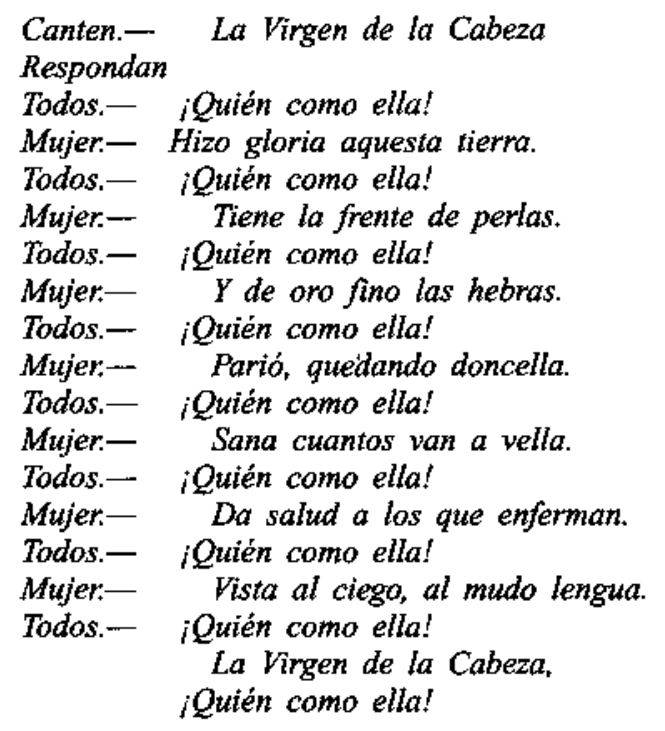

La tragedia del Rey don Sebastián (1593-1603), $B A E$, t. CCXXV, acto II, págs. 154-155.

Continúa en el tiempo, en ambiente americano, pero con reminiscencias clásicas (Febo, Diana), El Nuevo Mundo descubierto por Colón (1596-1603) y se inicia con un verso poemático, constituyendo el segundo el estribillo.

Canción de bodas creada por Lope con intención de dar color local, pues la denomina areito, tipo de canción narrativa americana que a veces se asimila al romance pero que, en las investigaciones realizadas, nunca ha tenido forma litánica.

Es curioso este estribillo que nace del primer verso, un octosílabo como el resto, excepto el estribillo, de él extraído, que es exasílabo.

A consecuencia de nuestra ignorancia y falta de buenas ediciones, generalmente salidas de manos y de manuscritos de actores, se nos presenta una duda: ¿deben repetirse los dos versos iniciales al final de la canción, o debe alterarse anteponiendo el último al penúltimo, que daria por resultado una perfecta regularización, sin que la forma que ostenta sea irregular? 
Cante una india y respondan otros:

$$
\begin{aligned}
& \text { [India].- Hoy que sale el sol divino, } \\
& \text { [Otros].- hoy que sale el sol. } \\
& \text { [India].- hoy que sale de mañana, } \\
& \text { [Otros].- hoy que sale el sol. } \\
& \text { [India].- se juntan de buena gana, } \\
& \text { [Otros].- hoy que sale el sol, } \\
& \text { [India].- Dulcanquellin con Tacuana, } \\
& \text { [Otros].- hoy que sale el sol, } \\
& \text { [India].- él Febo y ella Diana, } \\
& \text { [Otros].- hoy que sale el sol, } \\
& \text { [India].- a cacique tan hermoso, } \\
& \text { [Otros].- hoy que sale el sol, } \\
& \text { [India].- y a esposa de tal esposo, } \\
& \text { [Otros].- hoy que sale el sol, } \\
& \text { [India].- nuestro areito glorioso, } \\
& \text { [Otros].- hoy que sale el sol, } \\
& \text { [India].- consagre el canto famoso: } \\
& \text { [India].- Hoy que sale el sol divino, } \\
& \text { [Otros].- hoy que sale el sol. }
\end{aligned}
$$

(BAE, t. CCXV, acto II, pág. 142a).

En el mismo sentido funciona La hermosura aborrecida (1604-1610).

Los músicos han entonado un estribillo de dos versos: eneasílabo y octosílabo, éste (vámonos a coger rosas) será entonado por todos, lo cual nos afirma su forma coral. Es una forma más elaborada que el poema anterior, pues el estribillo inicial es cantado en el centro y final del poema: todos son versos octosílabos, excepto el verso inicial del estribillo (La mañana de San Juan, mozas); el resto son octosilabos: el primer grupo (versos 3 y 5) rimados en consonante (amanece-florece) y el verso 7 (olorosa) rima en asonante con el estribillo. La segunda mitad repite la misma estructura: versos 3-5 rimados en consonante (aves-suaves), mientras que el 7 (aqui convida la sombra) rima con el estribillo en asonante (o-a).

Tenemos aquí una canción: «interplay of voices between the musicians, a soloist, and chorus»" "que se injerta en la celebración del solsticio de verano, la noche de San Juan ${ }^{12}$.

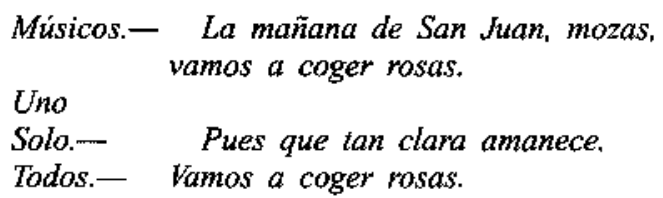

"G. Umpierre, Songs in the Plays of Lope de Vega, London, Tamesis, 1975, pág. 61.

12 J. T. Reid, «St. John's Day in Spanish literature», Hispania, XVIII, 1935, págs. 401-419. 


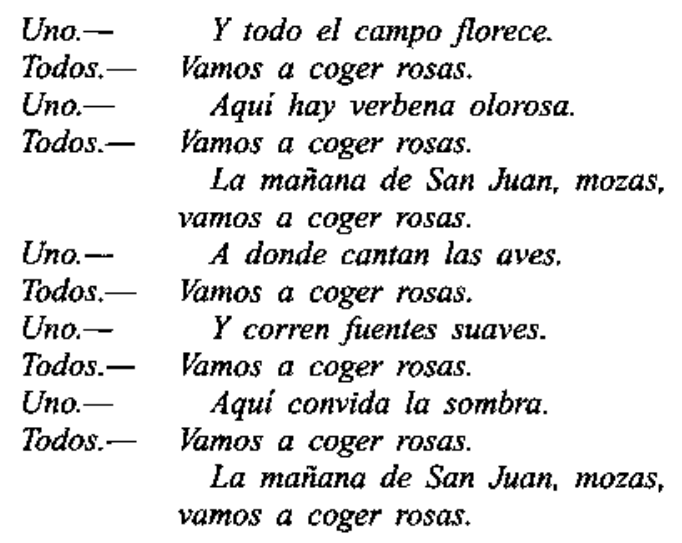

La hermosura aborrecida (1604-1610), N.Ac. VI, acto II, pág. 266.

La estructura métrica de octosílabos y pentasílabos, propios para la canción con la inclusión narrativa de cuatro versos que nos explican la ocasión:

Su esposa, que con él viene, por muchos años le goce, ... Marcela y él se desposen ...

nos indican que es una canción de bodas pero, a la vez, el protagonista, el Conde, es un Capitán valiente, a quien hoy recibe la multitud (¿de vasallos?) triunfalmente. Es, pues, también un canto triunfal.

Lope, con un virtuosismo extraordinario, mezcla asonancias en dos bloques: primero en $e-e$, segundo en $o-o$ y un tercer tipo en $o-e$, en que riman el estribillo, grito triunfal: $y$ viva el Conde, con otros tres versos: goce, desposen, flores.

Tema dúplice: mayo primaveral y amoroso, pero también tiempo, arcaico, de la fonsadera, comienzo de la guerra - que se observa en el calendario pictórico de San Isidoro de León (caballero con escudo); pero en el Renacimiento lo define así Pero Mexía: «los árboles comiençan a mostrar y dar su fruto, y las aves cantan y se alegran y haçen sonidos, y los hombres $\mathrm{y}$ otros animales se incitan y mueven a fiestas y plazeres y a produzir y procrear; muestrásse por esto este mes de mayo por un mancebo galanamente vestido, cabalgando a cavallo, en la mano un gavilán» ${ }^{13}$.

${ }^{13}$ P. Mexía, Silva de Varia Lección, ed. A. Castro, Madrid, Cátedra, 1990, 2 tomos, parte IV, cap. XIX, t. II, pág. 488 . 


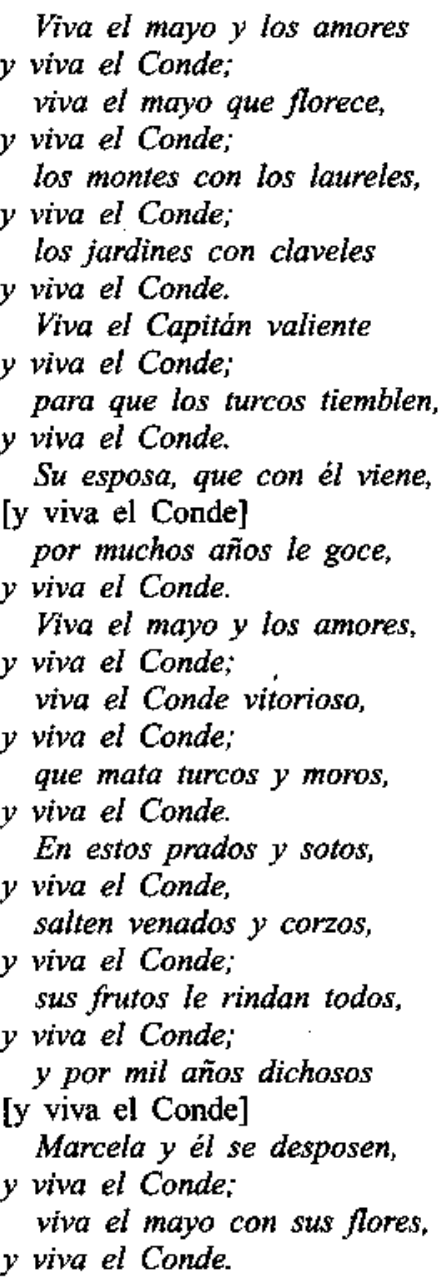

Ello dirá (1613-1615), N.Ac. V, acto III, pág. 65.

\begin{abstract}
Ahora el genial Lope se vale satínicamente de la forma litánica: comienza y finaliza con el estribillo, pero la introduce otra vez hacia el primer tercio: versos octosílabos para la fuerte narrativa enumerativa-m y heptasílabos agudos para el estribillo. Sólo dos tipos de asonancia: $e-o$ y $a$ $o$ pero, hacia el final, hay dos versos consonantes en -ado.

El tal caballero indiano - para más concreción, panameño- es Don Amor que, como en el que deseo: Poderoso caballero es Don Dinero, encandila a las damas con su rico atuendo.

Lástima es que haya que sustituir dos estribillos por causa de las malas ediciones. Sin duda, Lope lo hizo regular pero los manuscritos, recogidos de
\end{abstract}


comediantes, o los editores - hay ediciones antiguas y modernas que no los incluyen - han deturpado el texto que incluimos, críticamente, entre corchetes regularizando $-i y$ restituyendo? - la pureza de la forma litánica ${ }^{14}$.

Octavio, Miseno y Liseo se sientan: los Músicos canten y las dos [Nise y Finea] bailen ansí:

¿De dó viene, de dó viene?

Viene de Panamá.

¿De dó viene el caballero?

Viene de Panamá.

Trancelin en el sombrero.

Viene de Panamá.

Cadenita de oro al cuello.

Viene de Panamá.

En los brazos el grigiesco.

Viene de Panamá.

Las ligas con rapacejos.

Viene de Panamá.

Zapatos al uso nuevo.

[Viene de Panamá]

Sotanilla a lo turquesco.

Viene de Panamá.

¿De dó viene, de dó viene?

Viene de Panamá.

¿De dó viene el hijodalgo?

Viene de Panamá.

Corto cuello y puños largos.

Viene de Panamá.

la daga, en banda, colgando.

Viene de Panamá.

Guante de ámbar adobado.

Viene de Panamá.

Gran jugador del vocablo.

Viene de Panamá.

No da dinero y da manos.

Viene de Panamá.

Enfadoso y mal criado.

Viene de Panamá.

Es Amor: llámase indiano.

Viene de Panamá.

Es chapetón castellano.

Viene de Panamá.

En criollo disfrazado.

[Viene de Panamá].

¿De dó viene, de dó viene?

Viene de Panamá.

\footnotetext{
${ }^{14}$ G. Umpierre, Ob. cit., pág. 61.
} 
¿De dó viene, de dó viene? Viene de Panamá.

Deja las avellanicas, moro, que yo me las varearé.

El Amor se ha vuelto godo. que yo me las varearé.

Puños largos, cuello corto. Que yo me las varearé. Sotanilla y liga de oro. Que yo me las varearé.

Sombrero y zapato romo. Que yo me las varearé.

Manga ancha; calzón angosto. Que yo me las varearé.

Él habla mucho, y da poco. que yo me las varearé

Es viejo, y dice que es mozo. Que yo me las varearé.

Es cobarde, y mata moros, que yo me las varearé.

Ya se descubrió los ojos. Que yo me las varearé. Amor loco y amor loco. Que yo me las varearé. Yo por vos, y vos por otro. Que yo me las varearé.

Deja las avellanicas, moro, que yo me las varearé.

La dama boba (1613), N.Ac. XI, acto III, pág. 621 .

Para Díaz de Revenga es, quizá, «una de las mejores del teatro español» y no sólo por «su formulación monocorde, ligada a la lírica antigua y populan ${ }^{15}$, ya que el estribillo de las avellanicas se ha recogido en canciones de danza - similares a ésta- en Salamanca y Logroño ${ }^{16}$.

El mismo estribillo va a ser usado de dos formas diferentes: satírico en La dama boba y épico-fantástico y maravilloso en El villano en su rincón.

En la primera obra: continuando el tema del Amor, ahora se ha hecho godo, ennoblecido pero, como hidalgo, pobre, mal vestido, parlanchín y escaso, cobarde y presumido.

El estribillo será el segundo verso del enunciado inicial: dos versos -decasílabo y eneasílabo- que dan principio y fin al poema en octosílabos rimados en asonante $0-0$.

${ }^{15}$ F. J. Díez de Revenga, Teatro de Lope de Vega y lírica tradicional, Murcia, 1983, pág. 162.

${ }^{16}$ E. M. Turner, Lírica hispánica, Madrid, Castalia, 1966, tema n. ${ }^{\circ} 125$, pág. 219. 
Músicos (cantan):

$$
\begin{aligned}
& \text { Deja las avellanicas, moro } \\
& \text { que yo me las varearé, } \\
& \text { tres y cuatro en un pimpollo, } \\
& \text { que yo me las varearé. } \\
& \text { Al agua del Dinadámar, } \\
& \text { que yo me las varearé, } \\
& \text { All' estaba una cristiana, } \\
& \text { que yo me las varearé. } \\
& \text { Cogiendo estaba avellanas, } \\
& \text { que yo me las varearé. } \\
& \text { El moro llegó a ajudarla, } \\
& \text { que yo me las varearé. } \\
& \text { Y respondióle, enojada, } \\
& \text { que yo me las varearé. } \\
& \text { Deja las avellanicas, moro. } \\
& \text { que yo me las varearé. }
\end{aligned}
$$

Tres'y cuatro en un pimpollo, que yo me las varearé.

Era el árbol tan famoso, que yo me las varearé.

Que las ramas eran de oro. que yo me las varearé.

Hojas que le cubren todo, que yo me las varearé.

Eran de rubies rojos, que yo me las varearé.

Puso el moro en él los ojos, que yo me las varearé.

Quisiera gozarle solo, que yo me las varearé.

Mas dijole con enojo, que yo me las varearé.

Deja las avellanicas, moro, que yo me las varearé.

Tres y cuatro en un pimpollo, que yo me las varearé.

El villano en su rincón (1615),

a. III, esc. II, págs. 142-143.

Este poema-canción tiene todas las reminiscencias de la canción épica: el encuentro de don Bueso con su hermana la princesa Gudruna; del romance fronterizo: la cristiana y el moro; y toda la fantasía de los cuentos de hadas como el Romance del Infante Arnaldos, con el que coincide en la adjetivación: Que las ramas eran de oro (en algunas versiones: las cuerdas de oro torçal). 
Es, además, una canción de amor en que la «cristiana» rechaza el amor del «moro» que la requiebra en fuente de Dinadámar o, también, Dinadámor, fuente del amor, según Bataillon que se repite en El hidalgo bencerraje, La envidia de la nobleza y en Pedro Carbonero.

El simbolismo se extiende al árbol: ¿el cuerpo de la dama? que el moro: «quisiera gozarle solo» está, sin duda, en relación con la mítica rama de oro virgiliana. Pero la fantasía: tronco de planta, ramas de oro, hojas de rubíes son producto y recuerdo de los cuentos de hadas.

Poema satírico en el cual resalta y es eje fundamental la metáfora: el Amor - «arma la frente de lira»- correspondiente al gongorismo: «media luna las armas de su frente».

$$
\begin{aligned}
& \text { Uno-- Niña, guárdate del toro. } \\
& \text { Todos.- Que a mi mal ferido me ha. } \\
& \text { Uno.- Guárdate del toro, niña, } \\
& \text { Todos.- Que a mi mal ferido me ha. } \\
& \text { Uno.- Es amor que desatina. } \\
& \text { Todos.- Que a mi mal ferido me ha. } \\
& \text { Uno.- Arma la frente de lira. } \\
& \text { Todos.- Que a mi mal ferido me ha. } \\
& \text { Uno.- Al que coge sin guarida. } \\
& \text { Todos.- Que a mi mal ferido me ha. } \\
& \text { Uno.- Mata de celos y envidia. } \\
& \text { Todos.- Que a mi mal ferido me ha. } \\
& \text { Uno-- Niña, guárdate del toro. } \\
& \text { Todos.- Que a mi mal ferido me ha. } \\
& \text { Uno.- Guárdate, niña del toro. } \\
& \text { Todos.- Que a mi mal ferido me ha. } \\
& \text { Uno.- Da engaños y pide oro. } \\
& \text { Todos.- Que a mi mal ferido me ha. } \\
& \text { Uno.- Da vueltas al más dichoso. } \\
& \text { Todos.- Que a mi mal ferido me ha. } \\
& \text { Uno.- Al más cuerdo vuelve loco. } \\
& \text { Todos.- Que a mi mal ferido me ha. } \\
& \text { Uno.- Igualarlos quiere a todos. } \\
& \text { Todos.- Que a mi mal ferido me ha. } \\
& \text { Guárdate del toro, niña, } \\
& \text { que a mi mal ferido me ha. }
\end{aligned}
$$

La burgalesa de Lerma (1613), N.Ac. IV, acto, III, pág. 68 .

Una vez más resalta, frente a la absoluta regularidad, la variación que Lope imprime a sus poemas: dos partes simétricas de cuatro versos octosílabos cada una, rimados en asonante: la primera en $i-a$ y la segunda en $o-o$. 
Divididas por la repetición del estribillo inicial de cuatro versos asonantados en $-a$ y finalizado por la segunda parte del estribillo inicial.

Algo semejante en cuanto a la irregularidad, nos ocurre con el poema incluido en La juventud de San Isidro (1622). El estribillo es:

a) venga norabuena,

b) norabuena venga,

y si es perfectamente regular, al comienzo, al final han de pasar tres versos para que aparezca de nuevo.

Partamos del hecho de que el cambio de orden de palabras del estribillo es algo que hemos observado en parte en la Oración de los tres mancebos del bíblico Libro de Daniel ${ }^{17}$.

Hagamos constar que es un poema triunfal para la recepción victoriosa del Alcaide de Madrid, Gracián Ramírez. Recordemos que es el mismo tema del egipcio Himno en honor de Sesostris $I I I$ y que se despega de la tradición hispánica del carmina triunfalia que aparece en el s. XVI.

\footnotetext{
'Vengais norabuena,

duque mi señor.

pues venis vencedor
}

Auto del Sacrificio de Jeté ${ }^{18}$, Códice de Autos Viejos, t. I, pág. 422.

que imitará el mismo Lope de Vega:

Bien vengáis, el Conde

Bien vengáis triunfando.

¿Conde lidiadore,

bien vengáis, el Conde!

El Conde Fernán González, acto I, BAE, 196, págs. 122-113.

y otra vez más - siempre el prolífico Lope:

Sea bienvenido
el Comendadore
de rendir las tierras
y matar los hombres.

Fuente Ovejuna ${ }^{19}$

\footnotetext{
17 Sagrada Biblia, ed. Nárcar-Colunga, Libro de Daniel, parte I, cap. II, versículos 51-90.

18 M. Frenk, Corpus de la antigua lírica popular hispánica (s. Xv a xvil), Madrid Castalia, $1990^{2}, \mathrm{n}^{\mathrm{os}} 1227$ y 1228 A y B, págs. $587-588$.

${ }^{19}$ Lope de Vega, Fuenteovejuna, ed. A. Castro, Madrid, Espasa Calpe, 1935, acto I, págs. 39-40. Colección Unjversal.
} 
poemas que en el teatro solían glosarse en estrofas zejelescas o en romances pero que, con un sentido religioso - abundando en la forma y concepto del teatro del s. XVI- y en forma litánica, tendrá también Jorge de Montemayor: iSea bienvenido, sea!

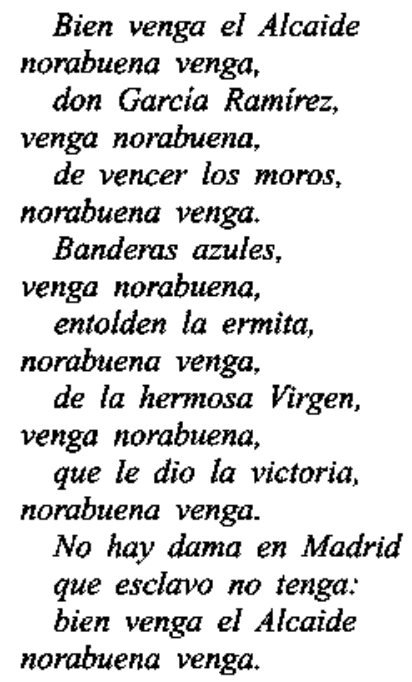

La juventud de San Isidro (1622), BAE, t. CLXXVIII, acto I, pág. 367.

Esta deliciosa canción, carmina triunfalia, del legendario García (o Gracián) Ramírez alude al milagro de la «Hermosa Virgen de Atocha, que le concedió la victoria y le devolvió la vida a su mujer e hijas que, por temor a la derrota» había degollado.

Se distingue por su doble estribillo, variación poco frecuente: «norabuena venga", "venga norabuena», alternado.

Venga norabuena, como canción de bienvenida, aparece en Los Guzmanes de Toral, Dos estrellas trocadas o Ramilletes de Madrid (que estudiamos en las formas irregulares) y en Las grandezas de Alejandro.

Se singulariza también por otras dos razones: son versos exasílabos sin rima, se apoya, sin duda, en la melodia y el canto coral, aunque no figuren para nada los músicos ni el solista ni el coro.

O en esta otra, que se asemeja por su forma y estructura a ésta, de $E l$ piadoso aragonés:

$$
\begin{gathered}
\text { Una vez.-Este niño se lleva la flor, } \\
\text { que los otros no. } \\
\text { Este niño tan garrido. }
\end{gathered}
$$




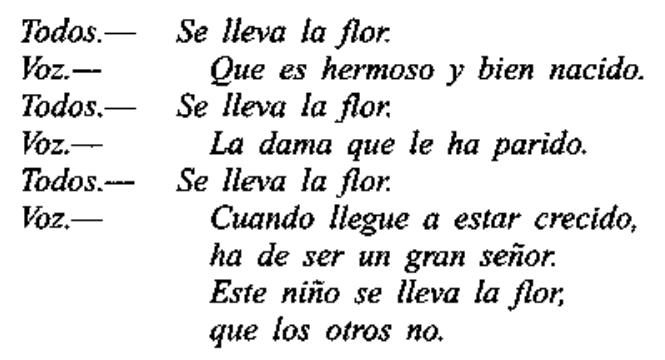

El piadoso aragonés (1626), A. II, versos $1077-1086^{20}$.

Aunque poema histórico en honor del bautizo del infante Don Fernando el Católico, puede fácilmente, al ser desgajado, convertirse en religioso.

Precisamente la edición de esta obra nos conserva todo el sentido musical -y casi todas las anotaciones-. Una voz entona el estribillo inicial:

Este niño se lleva la flor que los otros no

del cual se desgaja el segundo miembro del primer verso:

$$
\text { se lleva la flor }
$$

que, entonado por el coro, se convierte en la forma litánica.

Por otro lado, hay una pluralidad de versos (que musicalmente se igualarían) decasílabo, exasilabo (los estribillos), eneasílabo y octosílabo; la rima en los versos de la Voz: consonante en -ido y los estribillos asonantes en - $o$.

Nos recuerda la ligeramente irregular copla de La mejor enamorada: la Magdalena, pues cambia el género del demostrativo:

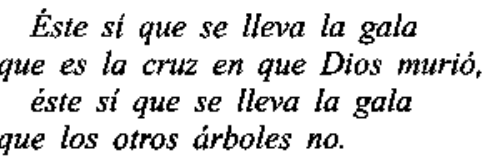

La mejor enamorada: la Magdalena (1609-1613), N.Ac. II, j. III, pág. $456 \mathrm{~b}$.

20 1077-1079: [EJ ms in] A divides this song between one singer and the chorus as I have done, giving Cantan in place de Todos for the first two verses. In B the first three verses of the song are assigned to Una Voz (pág. 57, nota).

1085-1088: [El ms] in B, the last four verses of the song are assigned to Una $\mathrm{Voz}$ (pág. 58n).

Edición critica de James Neal Greer, Austin (1951), University of Texas, Hispanic Studies, vol. III, págs. 57-58. 
Otro par de coplas más hemos hallado:

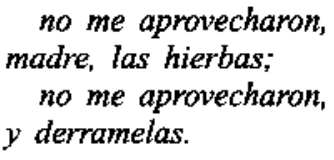

Y ésta, aunque quizá no sea de Lope:

Este si que es mayo famoso que los otros mayos no;

este si que se lleva la gala que los otros mayos no.

La esclava de su hijo (?),

N.Ac. II, j. I, pág. 161a.

Canción de vendimia

A la viña, viñadores, que sus frutos de amores son.

A la viña tan garrida, que sus frutos de amores son. ahora que está florida, que sus frutos de amores son a las hermosas convida con los pámpanos y flores. A la viña, viñadores, que sus frutos de amores son.

A la viña, viñadores, que sus frutos amores son. A la viña tan galana, que sus frutos amores son. de color de oro y grana, que sus frutos amores son cubre de vello y flor cana [que sus frutos de amores son] los racimos de dos en dos

A la viña y a las flores, que sus frutos amores son, $y$ racimos de dolores, [que sus frutos amores son]

A la viña, viñadores que sus frutos amores son.

El heredero del cielo, auto I, BAE, t. CLVII, págs. 183, 184 y 185. 
En Lope, la abundancia lírica es tan grande que en la forma litánica hay imitación afro-negra, irregularidad y regularidad; unas veces tiene sentido tradicional y otras es imitación y creación tradicionalista; no elude ningún tema: amoroso, religioso, festivo (onomatopéyico o lúdico), satírico, heroico o laboral.

La polivalencia creacional de Lope nos lleva a considerar la forma de sus estribillos; una sola obra se inicia con el estribillo El piadoso aragonés, forma arcaica y primigenia. Es el grito de atención del corego al coro para que a continuación lo repita tras cada verso. Así ocurre en las formas más antiguas como el Himno del desesperado o el Himno en honor de Sesostris ${ } I^{21}$. Sin duda, el estribillo se enunciaba al principio para que, aprendiéndolo el coro, pudiera repetirlo insistentemente tras cada verso $^{22}$.

En Lope sólo aparece esta única vez, el resto de los poemas - como veremos- se acerca más al Salmo 136, que se inicia con dos versos de los cuales el segundo será el estribillo.

Así ocurre en La hermosura agradecida, El villano en su rincón, Ello dirá; por ello no podemos considerar forma tradicional ni antigua los poemas de La burgalesa de Lerma y La victoria por la honra.

Otras observaciones nos surgen en relación con los estribillos: a veces son autónomos (exclamación, grito de júbilo o lúdico...).

La obra más importante en relación con la forma litánica es La dama $b o b a$, que se singulariza por dos aspectos:

1. La utilización de dos estribillos: uno de carácter geográfico, Viene de Panamá, que se relaciona, a través de los siglos con Iré a Santiago, de García Lorca.

2. Otro de tipo campesino, Deja las avellanicas moro, que se relaciona, sin duda ninguna, con el Nos olives, nos olives marroquí que, recogido por M. Fioux, fue difundido por Noel Salomón (págs. 500-501).

Por otro lado, este segundo estribillo se repite en El villano en su rincón (Acto III, versos 2069-2106), pero con carácter diferente.

Mientras los poemas de La dama boba tienen relación con la vestimenta del Amor y son bailables, la de El villano en su rincón es simplemente una canción.

\footnotetext{
${ }^{21}$ Cfr. mi artículo, La poesia litánica hasta Berceo, págs. 64-65.

22 En este sentido antiguo deberíamos incluir los poemas de negro, aunque quizá surgieran de la imitación de Simón Aguado, pero es que hoy sabemos de forma positiva de su origen centro-africano y su vitalidad actual. Por estas razones de arcaísmo deberemos incluir $\mathrm{La}$ victoria por la honra y El Capellán de la Virgen.
} 
Pero algo verdaderamente significativo es la utilización de variantes del mismo estribillo en lo que pudiéramos denominar dos coros y grupos musicales, juntos o enfrentados: El heredero del cielo, La juventud de San Isidro, Los ramilletes de Madrid.

No incluimos en esta valoración los poemas irregulares, esto es, aquellos que no repiten el estribillo, sistemáticamente, detrás de cada verso: El Arauco domado, La Araucana, Las Batuecas del Duque de Alba, La limpieza no manchada y El capellán de la Virgen.

De este grupo de poemas se distingue por su carácter un grupito que tienen también resonancias arcaicas. Las dos formas más antiguas son la funeraria y la heroica. Pues bien, Lope tiene cinco o seis poemas de loor o heroicos: El piadoso aragonés, Los ramilletes de Madrid, La tragedia del Rey don Sebastián (con la salvedad de su intencionalidad temática religiosa, al igual que La madre de la mejor), La juventud de San Isidro y Ello dirá.

Al lado de este grupo resalta el amoroso: La burgalesa de Lerma, La dama boba y uno de los dos de La victoria por la honra.

Lo curioso y significativo es que aparezcan estribillos festivos, jocundos - campesinos: El heredero del cielo, La hermosura aborrecida, El villano en su rincón y La dama boba.

Lope imita las formas tradicionales, convierte a ellas aspectos que nunca lo habían sido, pero su certera intuición poética hizo de ellos creaciones válidas que, a veces, por su riqueza creativa se igualaron a las tradicionales. Esta es la virtud del genio: transformar lo común en preciosa y bella materia.

Lástima grande es que no tengamos buenas ediciones de Lope y se pueda percibir el carácter coral; porque, así como en algunas ediciones aparece Todos como respondientes del estribillo, aquí $-\mathrm{y}$ en otros muchos poemasno aparece y puede plantearse la duda de si sería o no coral. Sin embargo, creo que, tras lo que llevamos dicho, no queda duda del carácter coral de los estribillos; por esta razón suplimos entre corchetes Todos.

\section{TIRSO DE MOLINA}

Tirso de Molina ( 1 1583?-1648) es, sin duda, el más fiel seguidor de Lope, pero sin decaer su propia personalidad. Creador innato, gustador de lo popular, aunque a veces en la figura del «bobo» o de donaire se recree en lo escatológico, utiliza, sin embargo, la forma litánica con un rigor, precisión y belleza admirables.

En tres obras hemos encontrado formas litánicas: La Santa Juana, I (1613) y II (1614) partes - un poema en cada una- y en el auto El colmenero divino (1621) $\rightarrow$ dos poemas. 
Dos de ellos son variaciones de un mismo tipo: la personificación y descripción de abril, que incide en un viejísimo tema ya presente en las bellas artes - San Isidoro de León-y la literatura - Libro de Alexandre, estr. 2554-2566; Libro de Buen Amor, estr. 1929-1300- que han sido estudiados por E. Mâle y Julio Caro Baroja. Coinciden también, casi de forma absoluta, los estribillos litánicos: «qué galán venis» (Santa Juana) y «muy galán venís) ( $E l$ colmenero divino); parece, pues, que Tirso recordó -cosa que hacía con frecuencia, aun autoplagiándose ${ }^{23}$ - el tema utilizado ocho años antes y lo repitió con leves variaciones, si bien en el primer poema se refiere a abril, el segundo, sin embargo, parece referirse al Colmenero; aunque la repetición de la estructura y de algún verso —casi ad pedem literae: «norabuena venga, venga» (El colmenero divino) y «norabuena vengais», abril (Santa Juana) - hacen más creíble la suposición de semi auto-plagio. Recordemos el sentido tradicional de carmina triunfalia que hemos encontrado en el s. Xvi y en Lope de Vega:

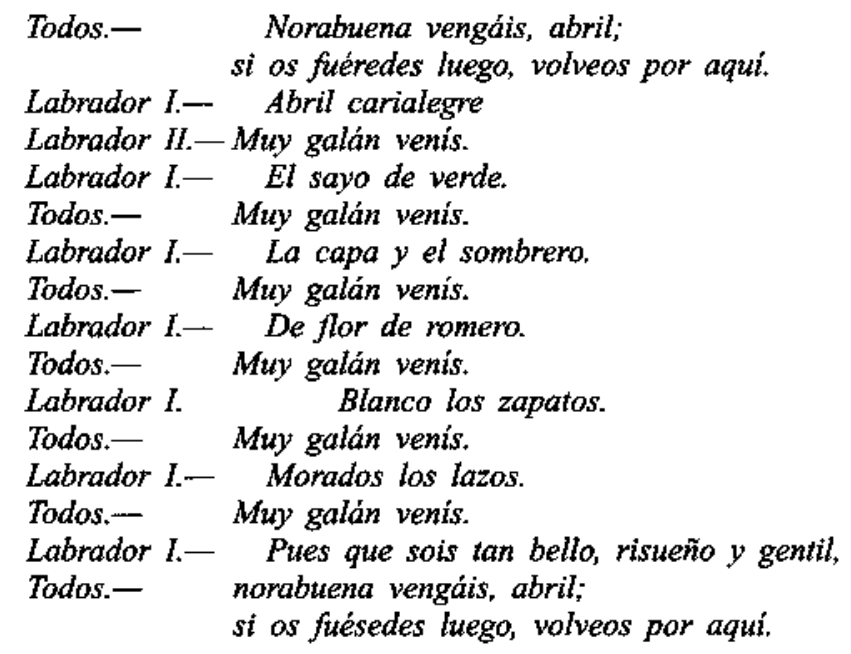

Santa Juana, I parte, acto I, esc. XIV ${ }^{24}$.

Como puede comprobarse, el recuerdo de este poema en el siguiente existe, pero es tanta la inventiva de los dramaturgos del $\mathrm{s}$. XVII, que son capaces de dar como obra absolutamente nueva algo que ya habian utilizado, no sólo por la forma sino, también, por el contenido:

\footnotetext{
${ }^{23}$ G. E. Wade, «Tirso's Self. Plagiarism in Ploł, H.R., IV, 1936, págs. 55-65.

${ }^{24}$ Tirso de Molina, Obras dramáticas completas, Ed. B. de los Ríos, Madrid Aguilar, 1946-1958. 3 vol., t. I, pág. 784 .
} 


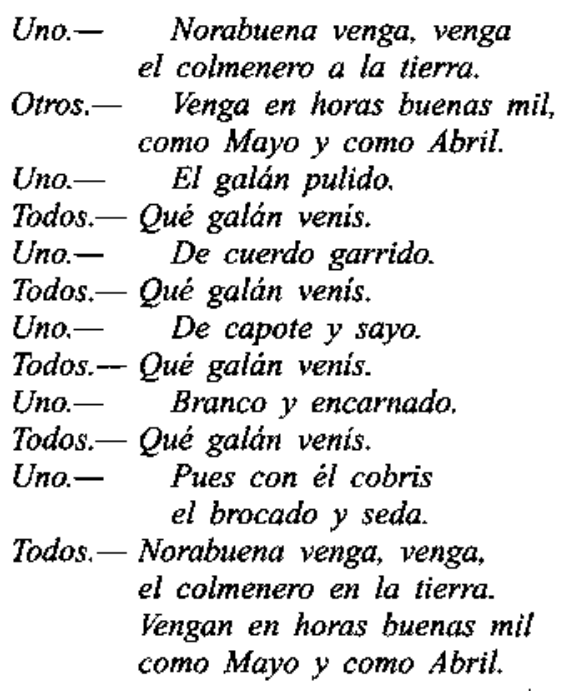

El colmenero divino ${ }^{25}$

Hay una cierta ingenuidad, y non sense, en el primer poema que alcanza una realización descriptiva perfecta en el segundo: la ingenuidad del primero se convierte en maestría en el segundo, si los colores en el primero aluden a las flores del romero (verde y morado), ahora el blanco y encarnado se referirán al colmenero (albura de pan y rojo de sangre, con toda la carga simbólica que acarrea). Pero también utilización de un estribillo ya tradicional: «qué galán venís».

Es tanto más curioso por cuanto el primer poema se inicia con un estribillo de dos versos y se termina con el mismo, pero acrecentado con un verso inicial nuevo, mientras que el segundo se inicia con dos dísticos, en forma de estribillo, que se repiten al final. De forma que, parece, estaba tan enraizada la forma litánica que no se consideraba como estribillo la repetición del verso uniformemente. Se había, pues, perdido - a causa de la difusión popular y teatral - el prístino sentido y se habia convertido en una pura fórmula, al menos en el quehacer artístico de Tirso, como puede observarse en este otro poema:

Todos (cantan): Trébole danle al niño, trébole, jay Jesús, qué olor!

Labrador 1.- Trébole y poleo

Todos:- Trébole

Labrador I- Alegre el bateo

Todos.- Trébole

25 Tirso de Molina, O.D.C., tomo 1, pág. $146 \mathrm{~b}$. 


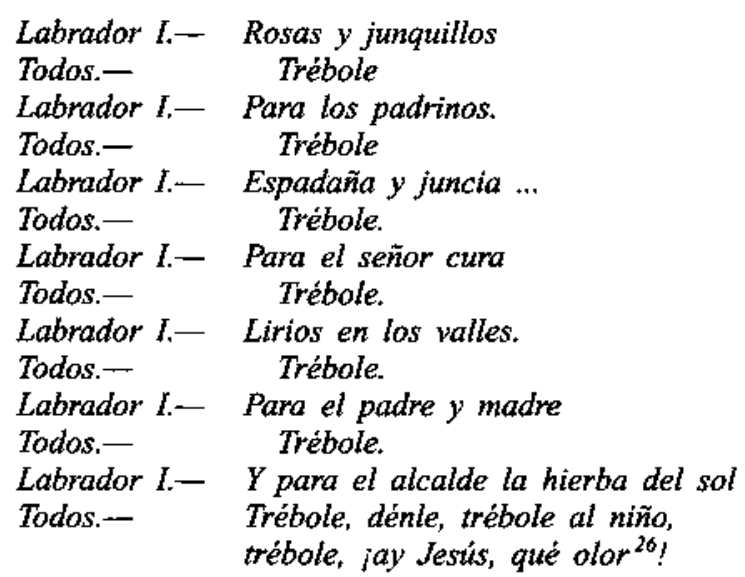

Santa Juana, II parte, acto I, esc. XVIII.

Habiendo vivido y estudiado Tirso en Toledo, y siendo el escenario de las Santa Juana, la Sagra toledana, correríamos el peligro - si no hubiéramos conocido otros poemas semejantes - de atribuir esta forma a la región castellana $-\mathrm{y}$ posiblemente aquí estuvo muy difundida en otro tiempo, entre el pueblo- de donde Lope ${ }^{27}$, Tirso, Vélez y Valdivielso, por ejemplo, la tomaron. Pero, sin duda, no fue así, como vemos por Simón Aguado y Calderón.

Algo verdaderamente caracteristico podemos observar en los poemas de la Santa Juana: el carácter coral de los poemas, y si bien ninguno comienza - como en las formas primitivas- por el estribillo que ha de repetir el coro (Todos), es curioso y significativo que en el primer poema del estribillo - «Muy galán venís»- lo entone el labrador II y luego le sigan Todos, mientras que en el tercero, el estribillo - de amplia raigambre popular en las fiestas de San Juan- se desprenda del estribillo inicial que en su dístico comienza por «trébole». Aún más, Cotarelo, Blanca de los Ríos y Pilar Palomo si bien ponen el estribillo «trébole» como coral, dan como versos octosílabos este poema porque completan el exasílabo con el esdrújulo "trébole», que daría lugar a un octosílabo, une así Jareño ${ }^{28}$ en las poesías líricas de Tírso en Clásicos Castalia, t. 17, pág. 62. Pero sería un caso único de poema canción monorrino, cuando en realidad son versos exasilabos: «trébole y poleo» más un estribillo bisílabo («trébole»); en su primera parte, el verso creado por el Labrador I coincide con el primer poema: «abril

\footnotetext{
${ }^{26}$ Tirso de Molina, O.D.C., t. 1, págs. 8396-840a,

${ }^{27}$ Lope de Vega utiliza un par de veces el estribillo "Trébole»; en Peribáñez (a. II, esc. III) y en El capellán de la Virgen (acto III, pág. 314b) y Tirso en La fingida Arcadia (a. III, esc. 2) y La villana de la Sagra (a. I, esc. 16).

${ }_{28}$ Tirso de Molina, Poesias liricas, Ed. E. Jareño, Madrid, Castalia, 1969, pags. 62-63.
} 
carialagre», también exasílabo, aunque seguido de un estribillo también exasílabo: «muy galán venís», y es metro también característico en el anterior poema de El colmenero divino: «el galán pulido».

Sin duda, mi forma de transcribir el poema es correcta, ya no sólo por la forma litánica, sino también por la parigualdad de la forma coral en los tres poemas y por el tipo de versos usados - el exasílabo- frecuente en la poesía popular y que hemos visto también en Los ramilletes de Madrid, de Lope de Vega: «venga el sol de España».

El último poema litánico de Tirso de Molina es el más irregular, pues está incrustado entre trísticos en $E l$ colmenero divino:

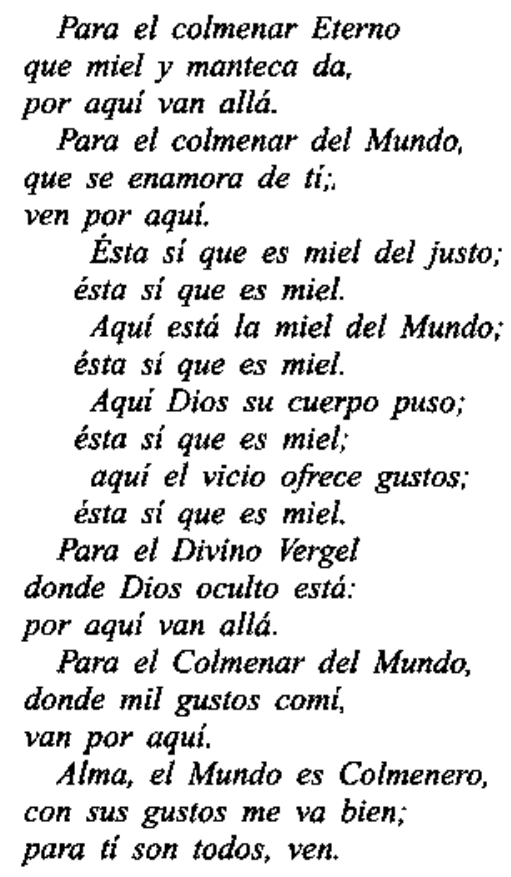

El colmenero divino ${ }^{29}$

Nuevamente se nos viene a las mientes el recuerdo de Lope: el estribillo de este poema - «ésta sí que es miel»— nos acerca a estribillo zejelesco: «ésta sí que es siega de vida - ésta sí que es siega de flon de $E l v a-$ quero de la Moraña. Tirso no sólo es seguidor de Lope en la estructura de la comedia, en la temática, en la utilización de la métrica, en la ideología, sino también en pequeños detalles - aunque importantes - como la utiliza-

${ }^{29}$ Tirso de Molina, O.D.C., t. 1, pág. 
ción de las formas populares y aun el recuerdo de estribillos que, quizá, fueran también de dominio mostrenco.

Creo que es conveniente hacer una puntualización: que Tirso sea discípulo de Lope no desdice de su propio poder creacional, porque obras como El condenado por desconfiado, El burlador de Sevilla y convidado de piedra o La prudencia en la mujer, son obras maestras, propias, auténticas creaciones de un grandísimo maestro teatral y poético. El principio de Lope es, digámoslo, adventicio en un creador de la capacidad indudable de Tirso de Molina y no desdice nada de su gloria el haber imitado a Lope, como le ocurre a Virgilio con Hesíodo o a Garcilaso con Virgilio, por ejemplo.

\section{JosÉ DE VALDIVIELSO}

José de Valdivielso (1560-1638), en su Ensaladilla de Navidad, incluye este trozo que, aunque no comienza por el estribillo, es regular en cuanto que repite el estribillo "viva la gala" tras cada verso; lejanamente nos recuerda el poema 839 de Alin: «a la gala de la panadera ...».

Tiene gran importancia porque significa que en la lírica culta, religiosa, del s. Xvı, lo mismo que había hecho Jorge de Montemayor, se utilizó, sacralizándola de nuevo, la forma litánica:

$$
\begin{aligned}
& \text { Viva la gala de la zagala } \\
& \text { viva la gala, } \\
& \text { de la graciosa morena, } \\
& \text { viva la gala, } \\
& \text { de gracia y de gracias llena, } \\
& \text { viva la gala, } \\
& \text { que en aquella noche buena } \\
& \text { viva la gala, } \\
& \text { libra al mundo de la mala, } \\
& \text { viva la gala, } \\
& \text { Viva la gala de la zaga, } \\
& \text { viva la gala. }
\end{aligned}
$$

Ensaladilla de Navidad ${ }^{30}$

Los dos últimos versos en la edición de Aguirre tienen orden inverso, lo cual parece mal pues si comparamos con el siguiente, veremos que tiene el mismo orden del comienzo.

\footnotetext{
30 José de Valdivielso, Romancero espiritual, Ed. J. M. Aguirre, Madrid, Espasa-Calpe, 1984 , págs. 223-224.
} 
Paralelo, pero más regular que el de Lope de Vega en El piadoso aragonés, aparece este villancico litánico en la Ensaladilla de Navidad (págs. 224-225):

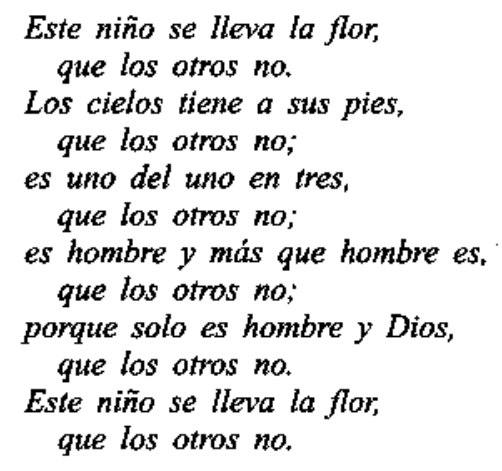

Ensaladilla de Navidad ${ }^{31}$

En el mismo sentido religioso da Valdivielso al "carmen triunfal» en que mezcla ese estribillo en forma de copla inicial con otro original suyo: «la más linda flor», que alude a la Virgen, lo mismo que el anterior aludía al Niño Jesús:

$$
\begin{aligned}
& \text { Venga en hora buena } \\
& \text { la flor de mayo, } \\
& \text { venga en hora buena } \\
& \text { la más linda flor, } \\
& \text { Venga en hora buena } \\
& \text { la más linda flor, } \\
& \text { la que es toda hermosa, } \\
& \text { la más linda flor. } \\
& \text { La hermosa morena, } \\
& \text { la más linda flor, } \\
& \text { morena graciosa, } \\
& \text { la más linda flor. } \\
& \text { Pues como a su esposa, } \\
& \text { la más linda flor, } \\
& \text { la hace Dios el plato. } \\
& \text { Venga en hora buena ... } \\
& \text { Venga del desierto } \\
& \text { la más linda flor, } \\
& \text { de riquezas llena, } \\
& \text { la más linda flor, } \\
& \text { al Dios que encubierto, } \\
& \text { la más linda flor, } \\
& \text { se le da en la cena. }
\end{aligned}
$$

I! Idem, págs. 224-225. 
la más linda flor.

de si la enagena,

la más linda flor,

con este bocado.

Venga en hora buena ...

Valdivielso, Ensaladilla de la esposa $y$ el esposo ${ }^{32}$

Pero no era Valdivielso persona que se conformara con caminos trillados y en el siguiente poema, dedicado a la Natividad, de su Romancero espiritual, se nos mostrará, hasta cierto punto, anárquico ya que mezclará varios estribillos: «morena», «zon, zon»y, una vez, «María». Lo sitúa al final del poema como quisiera culminarlo, pero indudablemente es un tanto confusa la utilización de la forma litánica, más visual que musical y bailable, ya que sigue a una narración bastante extensa y no es, tampoco, sistemática la repetición ora porque no siempre es tras cada verso, ora porque no hay alternancia entre los estribillos «morena» y «zon, zon», ya que a veces se repite dos o tres veces seguidas el «morena» o es sustituido en un caso -que ya parecía sistemática la altemancia- por «Maria», y nunca ocurre algo semejante con el estribillo «zon, zon», de carácter lúdico y musical pero, desde luego, no bailable por el contexto y connotaciones que comporta.

Harás unas coplas

Que al chicote leigas;

Que otras del zon, zon

$Y$ de la morena

Traigo componidas

Tú me las enmienda.

Si á tan dulces pechos Morena

El niño duerme,

¿Qué sabroso ha de hallarle, Morena,

Cuando te recuerde!

Zon, zon

Misericordioso,

Morena,

Adán lo espere,

Zon, zon;

Porque misericordias, Morena,

Mama en la leche,

Zon, zon;

${ }^{32}$ Valdivielso, Ob. cit., pág. 119. 
Temblábale el cielo,

Morena,

De puro bravo,

Zon, zon;

y ya tamañito,

Morena,

Le está temblando.

Si el recién nacido,

Morena,

Llora de amores,

iQué piadoso le tienen,

Morena,

De hallar los hombres!

Zon, zon:

Tierra sois, Maria,

Morena,

Mas de pan llevar,

Zon, zon;

Que la tierra morena.

Maria

lleva el mejor pan,

Zon, zon;

La Iglesia le espera,

Morena,

Porque dél, Señora,

Zon, zon;

Para todas las misas,

Morena,

Quiere hacer hostias,

Zon, $z o n^{33}$.

Los dramaturgos del s. XVII, seguidores de Lope, continuaron y repitieron, de forma originalísima a veces, los hallazgos dramáticos y líricos de Lope que, en esencia, frecuentemente estaban en la raiz popular. El genio del Fénix los transformó en moneda corriente, los elevó a categoría literaria y los hizo vitales para la tragicomedia española, siguiendo en cuanto a la forma litánica los mismos derroteros que el teatro clásico griego.

\section{Damián Salucio del Poyo}

Así aparece en Damián Salucio del Poyo:

Ambos.-Por la salud, por la salud

Uno.- Los que no tienen poco ... Ambos.-Por la salud;

${ }^{33}$ Valdivielso, Ob. cit., págs. 325-326. 


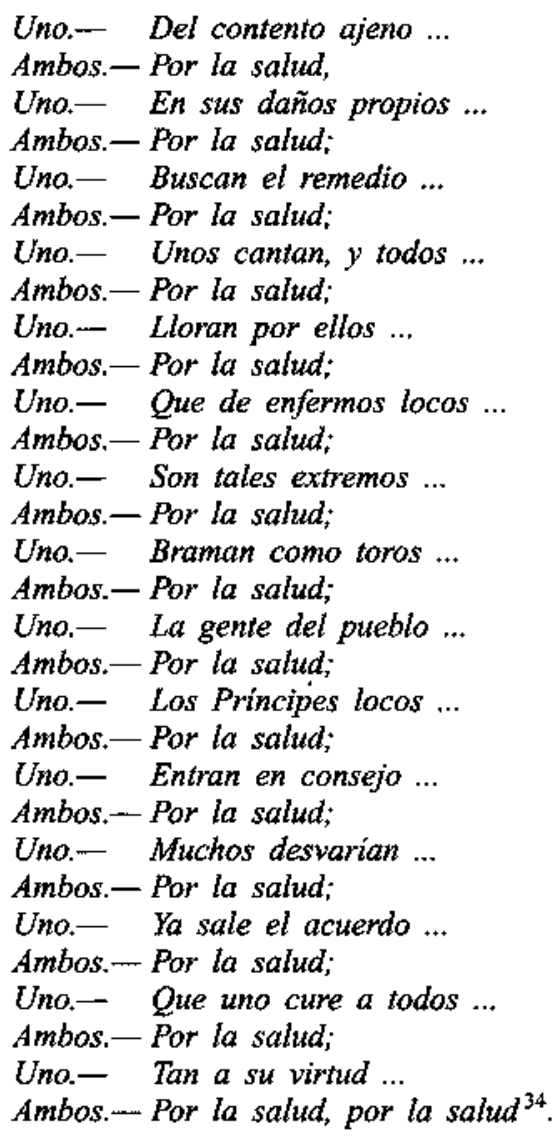

La vida y muerte de Judas (1985), j. III, versos $486-518$.

\section{Luis Vélez de Guevara}

Así, Luis Vélez de Guevara (1579-1644) inchuye en La serrana de la Ve$r a$ un viejo romance que, con forma litánica, hace resaltar, renovando el popular «allá en garganta la Olla» que narra, como un viejo mito de femina silvaticae, las aventuras de una serrana, bandolera, que tiene sus raices, también, en las serranillas medievales.

¿Quién como ella,

la serrana de la Vera.

34 D. Salucio del Poyo, Comedias, Ed. C. Hernández, Murcia, Academia Alfonso X, 1985, págs. $220-222$. 
$A$ dar flores sale al prado

la serrana de la Vera, bizarra puesta a caballo

la serrana de la Vera.

En crenchas lleva el tocado

la serrana de la Vera, ojos hermosos rasgados,

la serrana de la Vera; lisa frente, rojos labios,

la serrana de la Vera: pelo de ámbar, blancas manos,

la serrana de la Vera cuerpo genzor y adamado

la serrana de la Vera. ¡Quién como ella,

la serrana de la Vera! $A$ dar flores sale al valle

la serrana de la Vera. genzor cuerpo, hermoso talle,

la serrana de la Vera. Su belleza y su donaire,

la serrana de la Vera, viene enamorando el ayre,

la serrana de la Vera.

Sus ojos negros y graves,

la serrana de la Vera, no hay quien mire que no adame

la serrana de la Vera, y le dé un galán amante,

la serrana de la Vera, para que con ella case la serrana de la Vera, y para a los doce pares

la serrana de la Vera.

¿Quién como ella,

la serrana de la Vera! ${ }^{35}$

El poema, retrato con tintes de elogioso, prólogo a la tragedia que después se desarrollará, según el romance, en la espléndida tragicomedia de Vélez, consta de dos partes: primera, hasta el verso 16 , con rima en $a-o$ y segunda hasta el final, con rima en a-e, enmarcadas por un estribillo inicial: "quién como ella / la serrana de la Vera», que se repite en los versos 17-18 y los dos finales. Observamos que el discipulaje de Lope se muestra claramente, incluso, en el primer verso «quién como ella», que he-

${ }^{35}$ L. Vélez de Guevara, La Serrana de la Vera, Ed. Menéndez Pidal y M. Guyri, Madrid, CEH, 1916, Teatro Antiguo Español, Acto I, págs. 10-11. 
mos encontrado ya en La tragedia del Rey don Sebastián (1595-1603) como segundo verso «la Virgen de la Cabeza / ¡quién como ella!» y estribillo litánico. Pero observamos la regresión al sentido profano de elogio admirativo a la «feminae silvaticae», salvaje o diabólica.

Sin embargo, Vélez utilizará la más pura forma litánica en sentido religioso en El lego de Alcalá:

$$
\begin{gathered}
\text { Músicos.- Allá van los de la vela, } \\
\text { Señora de la Salzeda. } \\
\text { Allá van a vuestra casa, } \\
\text { allá van los de la aldea, } \\
\text { Señora de la Salzeda, } \\
\text { a daros la bien llegada, } \\
\text { Señora de la Salzeda. } \\
\text { Todos.- Allá van los de la vela, } \\
\text { Señora de la Salzeda. } \\
\text { Solo.- A daros la bien venida, } \\
\text { Señora de la Salzeda, } \\
\text { Todos.- Allá van los de la vela, } \\
\text { Señora de la Salzeda }{ }^{36} .
\end{gathered}
$$

Desde el punto de vista meramente de transcripción, es perfectamente litánica, pero desde el estructural vemos que no es tal, pues el estribillo «Señora de la Salzeda» ora es entonado o dicho por un cantor o por todos. Se iniciaba aquí ya la descomposición músico-danzable de la forma.

\section{FRANCISCO DE ROJAS ZORRILLA}

Más joven que Calderón y discípulo suyo es Francisco de Rojas Zorrilla (1607-1648) y también tiene un par de poemas, uno no muy regular:

$$
\begin{aligned}
& \text { Esta es Blanca como el sol } \\
& \text { que no la nieve no; } \\
& \text { esta es hermosa y lozana } \\
& \text { como el sol, } \\
& \text { que parece a la mañana, } \\
& \text { como el sol; } \\
& \text { que aquestos campos alegra, } \\
& \text { como el sol, } \\
& \text { con quien es la nieve negra } \\
& \text { y del almendro la flor; } \\
& \text { esta es Blanca como el sol. } \\
& \text { que la nieve no }{ }^{37} \text {. }
\end{aligned}
$$

\footnotetext{
${ }^{36}$ L. Vélez de Guevara, El lego de Alcalá, en Laurel de Comedias, 1657, Acto I, fol. 55b.

${ }^{37}$ F. Rojas Zorrilla, Garcia del Castañar, ed. Barker, Cambridge, 1935, j. I, escena V, pág. 11.
} 
Pero otro es una estupenda canción de negros perfectamente coral, así marcado en el mss:

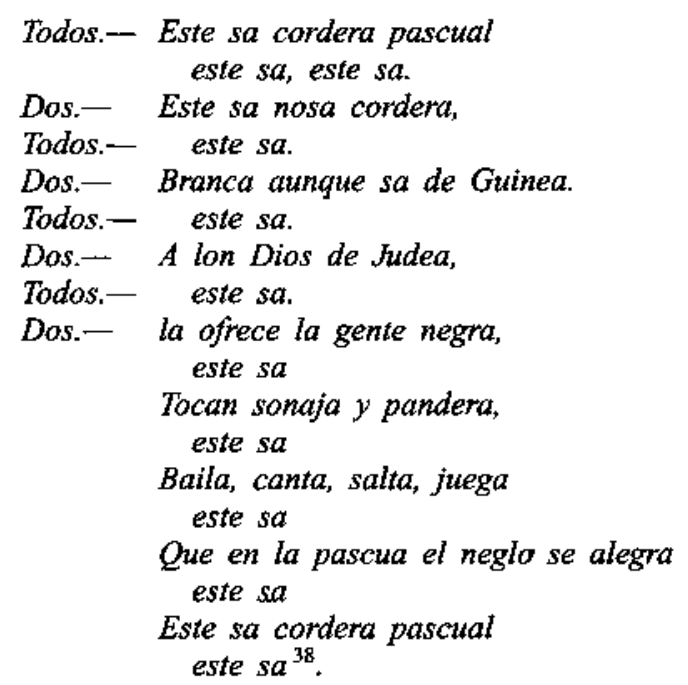

\section{Luis QuiÑones DE BENAVENTE}

Luis Quiñones de Benavente ( ¿1652?) en el entremés de La Capeadora, introduce una forma burlesca, típica de letrilla, pero quizá influenciada por tipos como el entremés de Los Negros de Simón Aguado. Nos muestra hasta qué punto se había popularizado la forma y cómo había evolucionado y degenerado desde lo heroico y fúnebre a lo lírico y burlesco. Normal en todo el transcurso literario.

$$
\begin{aligned}
& \text { Que se caiga la torre } \\
& \text { de Valladolid, } \\
& \text { como a mi no me coja, } \\
& \text { ¿qué se me da a mi? } \\
& \text { Si me pide una dama, } \\
& \text { ¿qué se me da a mi? } \\
& \text { Si lo paga su fama } \\
& \text { ¿qué se me da a mi? } \\
& \text { Si el lance es apretado, } \\
& \text { ¿qué se me da a mi? } \\
& \text { Si me llama apocado, } \\
& \text { ¿qué se me da a mi? }
\end{aligned}
$$

${ }^{38}$ Hierusalem castigada, Jornada II, ms. fol. 21. 


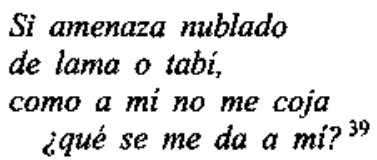

\section{Pedro Calderón de la Barca}

El último texto teatral del s. Xvil se lo debemos a D. Pedro Calderón de la Barca (1600-1681), que lo incluye en El Pintor de su deshonra (t. II, esc. XV, t. I, pág. 88), fechada entre 1648 y 1650 . Es un canto amebeo en que la primera parte la canta una doncella y la segunda un joven pero es, a la vez, canto de baile, expresamente se dice. Tiene, por otra parte, la característica de - sin duda, por las deturpaciones del catalán, pues, como se observa, es mezcla catalano-castellana- haber sido recogida del fondo popular, quizá en Lérida y en 1642, como piensa Romeu Figueras ${ }^{40}$.

Extraña Romeu que no tenga estribillo inicial («no tiene refrán inicial»), pero ya hemos visto con anterioridad que es frecuente este tipo de poema litánico, como también debe ser de raigambre popular el paralelismo entre ambas partes.

Prueba de la difusión e importancia en la época nos la revela Calderón ya que, por su carácter, era poco amigo de la poesía de tipo tradicional. A veces acoge un romance culto - de Góngora, por ejemplo- y lo glosa ( $E l$ Príncipe Constante), pero es escasísima su atención a lo folklórico y, por ello, es importantísima esta forma imperfecta y atípica que nos muestra la enorme difusión que esta forma debió tener.

Por otro lado, el estribillo «tararera» es onomatopéyico, dice Romeu. Yo pienso más bien en una lúdica y sin más significación que la puramente musical, como algunos otros populares que hemos visto: «zúmbara que zumbará», «obebé», «sambara culemba».

Es, pues, aunque imperfecto un canto amebeo-responsorial, coral, paralelístico y litánico. No creo que sea mal abolorio para tan larga tradición. Las diversas formas se han interpretado en el alma popular.

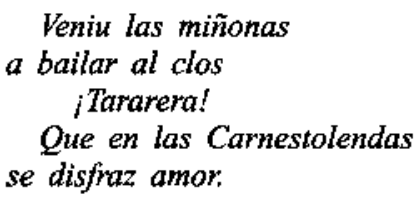

\footnotetext{
${ }^{39}$ La Capeadora (II." Parte) en Cotarelo, E., Colección de Entremeses, loas, bailes... Madrid, Bailly-Baillere, 1911, NBAE. Tomo I, vol. $2 .^{\circ}$, págs. 554-555.

40 J. Romeu Figueras, «El cantar paralelistico en Cataluña. Sus relaciones con el de Galicia y Portugal y el de Castilla», en Anuario Musical, 9, 1954, págs. 54-55.
} 


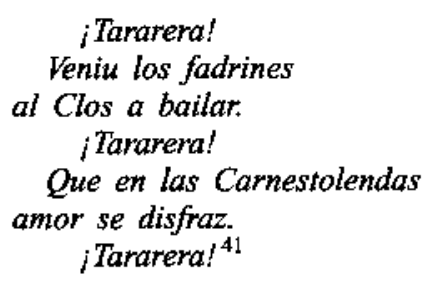

El pintor de su deshonra.

\section{S. XVIII}

El siglo de las luces, filosófico, disputador y prosaico, agostó la poesía popular y raramente se descubre 0 , si lo hace, es con fines extraños a su esencia, como cuando se escribe la vida de un Santo - San Benito de Palermo- en seguidillas. El carácter de Benegasi y Luján, autor de tal monstruo, queda asi definido. Pero la poesía popular permaneció latente y reapareció más tarde e, incluso - en algún rincón apartado- de forma espontánea surgió algún poema-canción y danza como éste:

Canto congo de Cabildo para tres tambores

(Tambor «mula»

tambor «caja

tambor "tumbador")

(To que)

Engó teramene!

Jabre cutu güiri mambo.

¿Engó teramene!

Jabre cutu guiri diambo.

¿Engó teramene!

Jabre cutu güiri dinga.

¿Engó teramene!

Jabre cutu muana inquén diame.

¡Engó teramene!

(Palabras)

- ¿Elo güire? ¿Elo güire?

Su messé, la cabayero,

dispénseme la molettia;

ba jablá poco cuetto,

ni son cosa dé mietto

ni biene co la lía

${ }^{41}$ Pedro Calderón de la Barca, Obras completas, Ed. Valbuena Briones, Madrid, Aguilar, 1966, 3 vols., t. I, Jornada II, pág. 888 a. 
congo de brujilla.

Yo mismo soy cabanga,

mimo cheche lucuanda.

¡Yambó chiriqui engunde!

Movimbe prende lengua.

Tambó manda suppende ...

¡Cautibo, casa malo!

¿Engó teramene!

Jabre cutu güiri mambo.

¡Engó teramene!

Jabre cutu güiri diambo.

¡Engó teramane!

Jabre cutu güiri dinga.

¡Engó teramene!

Jabre cutu muana inquén diame.

¿Engó teramene! ${ }^{42}$

Sensemayá.

Es significativo este poema: la mezcla de dialectos negros y castellano dialectal, el sentido musical del poema; el comienzo por una forma litánica iniciada por el estribillo «engó teramene» -que, en repetición de toda la estrofa cierra, también, el poema-, el sentido anafórico y repetitivo en los versos litánicos, dan un valor tanto más extraordinario -y yo diria hasta primigenio- a esta composición. Creo que es original y propio de negros que reproducen atávicas canciones, sin mezcla del sentido religioso litánico, ni poético y teatral hispano. La razón que me mueve a pensar así es la postración en que se hallaba la poesía popular española. Podría dudarse si entre los emigrantes hispanos persistía la forma popular de algunas canciones litánicas y a su ejemplo resurgió la forma negra, que trajo a sus mentes recuerdos gratos de tiempos pasados. Pero aunque así fuera, sin duda la añoranza tuvo que ser más fuerte que la presencia hispana. Ésta se producirá -más intensamente-- cuando los poetas cultos, acostumbrado su ódo a la forma sacral, y su mente imbuida de la forma popular poética y teatral se percaten del valor que - poética y musicalmente- tenía.

Ese sentido originario - negro - lo hemos percibido también en los extraños balbuceos -incluso con mezclas dialectales- de Simón Aguado: Los Negros (1602) y Lope de Vega: El capellán de la Virgen.

${ }^{42}$ A. Albornoz y Luis J. Rodriguez, Sensemayá. La poesía negra en el mundo hispano hablante, Madrid, Orígenes, 1980, Cantos del Cabildo (s. Xvıit), págs. 57-58. 


\section{ANTONIO ZAMORA}

Lo curioso y característico, en general, es la irregularidad que comienza en don Antonio Zamora, en No hay plazo que no se cumpla, ni deuda que no se pague. Pizpireta canta la siguiente canción:

Más que te lleve, Gileta, Cupido

que es diablo que sabe jugar los desdenes, más que te lleve

$y$ que en su infierno apacible padezcas [más que te lleve]

el mal de celosa, el tormento de ausente. más que te lleve.

[...]

Más que te lleve, Gileta, Cupido,

que es cosa terrible el matar por querete, más que te lleve,

$y$ en pago del fuego con ardores $y$ burlas, [más que te lleve]

su fuego te abrase, su incendio te queme; más que te lleve ${ }^{43}$.

La Pizpireta canta sola, no hay coro; es una canción semiculta, en que lo popular - lo litánico- tiene poca trascendencia; las ediciones de don Antonio Zamora, en general, son perversas y no se puede estar seguro de su fiabilidad; y, en fin, con cuán poco, dos adiciones, se consigue regularizar la forma litánica.

Comienza, pues, con el pentasílabo inicial del que parecería ser el estribillo y no lo es, pero si lo restauramos en el quinto lugar, resulta una forma litánica regular. Estas deturpaciones vulgares son frecuentes en este siglo.

\section{Diego de ToRres VIlLARRoel}

Algunas veces, sin embargo, en poetas conservadores como don Diego de Torres Villarroel, aparece la forma perfecta:

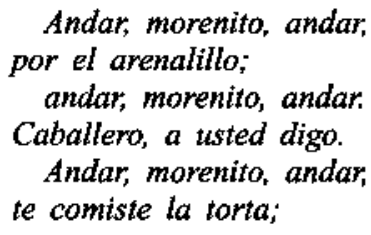

${ }^{43}$ Jornada Il, BAE, t. XLIX, pág. 425b. 
andar, morenito, andar, no te comerás otra ${ }^{44}$.

Su carácter popular está perfectamente claro y su forma es tan regular como la de este villancico:

$$
\begin{aligned}
& \text { A cortejar al niño } \\
& \text { ciego he venido. } \\
& \text { A cortejar el niño, } \\
& \text { carambú, carambelo. } \\
& \text { A cortejar al niño } \\
& \text { que por Dios que le quiero }{ }^{45} \text {. }
\end{aligned}
$$

De tal manera Torres ha trasteado por mesones y posadas que incluso se ha dejado penetrar esas formas populares que hasta se anticipa en el tiempo; el siguiente estribillo nos habla del destierro en Orán y de las Tonadillas, estamos en 1737, cuando aún los mejores músicos como Rodríguez Hita, Luisón o Guerrero, no.los han puesto de moda en el teatro:

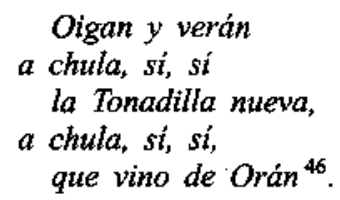

El buen gusto de don Julio Cejador lo percibió entre la balumba de tonadillas antes que don José Subirá las pusiera en orden y a disposición del lector y músico:

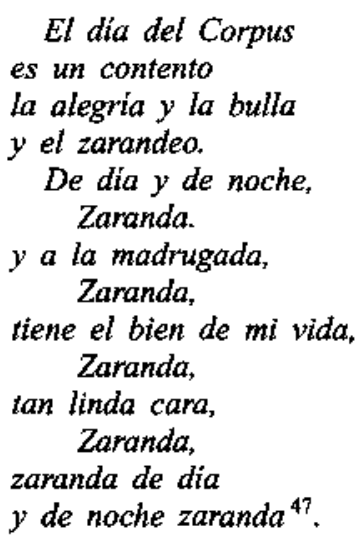

${ }^{44}$ D. Torres Villarroel, Talia, 1737. Sainete del Palla, pág. 113.

45 Idem, Villancico de los figurones ridiculos de Salamanca, pág. 190

46 Idem, Sainete de la Peregrina, pág. 128.

47 J. Cejador, La verdadera poesía castellana, Madrid, 1926, tomo VI, pág. 215: «Tonadilla de La oposición a las bodas" (1749). 
$R F E$, LXXXI, 2001 LA FORMA LITÁNICA EN EL TEATRO. SIGLOS XVI-XVIII

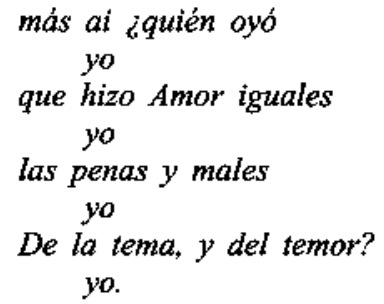

Iustificación de temores, puesto en música por el P. M. F. Luis de Cristo.

Ruena de Tersicore, tomo. XI, t. II, pág. 60 Sólo el estribillo R-i-37 